\title{
Adsorption and Corrosion Inhibition Characteristics of Some Nicotinamide Derivatives on Mild Steel in Hydrochloric Acid Solution
}

\author{
M. P. Chakravarthy and K. N. Mohana \\ Department of Studies in Chemistry, University of Mysore, Manasagangotri, Mysore 570 00, India \\ Correspondence should be addressed to K. N. Mohana; drknmohana@gmail.com
}

Received 31 December 2013; Accepted 4 February 2014; Published 10 March 2014

Academic Editors: I. Obot and M. Z. A. Rafiquee

Copyright @ 2014 M. P. Chakravarthy and K. N. Mohana. This is an open access article distributed under the Creative Commons Attribution License, which permits unrestricted use, distribution, and reproduction in any medium, provided the original work is properly cited.

\begin{abstract}
The present investigation includes the study of corrosion inhibition effect of $\mathrm{N}$-(1H-Indol-3-ylmethylene)-nicotinamide (IMN) and $\mathrm{N}$-(3,4,5-trimethoxy-benzylidene)-nicotinamide (TMN) on mild steel in $0.5 \mathrm{M} \mathrm{HCl}$ by mass loss and electrochemical measurements. The obtained results showed that inhibition efficiency increased with the increasing concentration of inhibitors and decreased with increase in temperature and immersion time. Potentiodynamic polarization curves indicate that both IMN and TMN were acting as mixed type of inhibitors. Langmuir adsorption isotherm model was employed to determine the equilibrium of adsorption for inhibiting process in both inhibitors. Nyquist plots revealed that, as the concentration of the inhibitors increases, double layer capacitance $\left(C_{\mathrm{dl}}\right)$ and corrosion current $\left(i_{\text {corr }}\right)$ decreases, while polarization resistance $\left(R_{p}\right)$ increases. Various thermodynamic parameters for the adsorption of inhibitors on mild steel were computed and discussed. The passive film formed on the metal surface was characterized by FTIR, EDX, and SEM.
\end{abstract}

\section{Introduction}

Mild steel (MS) is cheap, strong, stiff, and widely used engineering material because of its good mechanical properties. It is the most important structural material exposed to outdoor conditions especially in acidic media [1] where corrosion is considerably more severe. Because of the general aggressiveness of acid solutions, inhibitors are commonly used to reduce the corrosive attack on metallic materials $[2,3]$. Therefore, selection of an appropriate inhibitor ranging from rare earth elements [4] to organic compounds [5-8] for specific environment and metal is of great importance. In other words, the efficiency of these compounds is attributed to their steric factors, functional groups, lone pairs of electrons present on the hetero atoms, and pi-orbital character of donating electrons which determine the type of interaction between organic molecules and the metallic surfaces. The presence of corrosion inhibitors in a little amount blocks the corrosion sites and enhances the adsorption process, thereby increasing the life time of the metallic materials $[9,10]$.
A review of the literature reveals that the applicability of organic compounds as corrosion inhibitors for MS in acidic media has been recognized for a long time. A large number of organic compounds, particularly those containing nitrogen, oxygen, or sulphur in a conjugated system, are known to be applied as inhibitors to control acid corrosion of iron and steel. The inhibition process has been shown to occur via inhibitor adsorption, and the efficiency of an inhibitor strongly depends on the structure and chemical characteristics under particular experimental condition.

A large number of organic compounds containing nitrogen, oxygen, or sulphur have been used as inhibitors to control acid corrosion of iron and steel $[11,12]$. The adsorption characteristics of organic molecules are also affected by sizes, electron density at the donor atoms, and orbital character of donating electrons [13-16]. Several organic compounds such as thiourea derivatives [17], thiophene derivatives [18], fatty acid oxadiazole derivatives [19], sulphonamide compounds [20], triazines [21], pyridine Schiff bases [22], fluoroquinolones [23], phenylhydrazone derivatives [24], fatty acid 
<smiles>[NH3+]C(=O)c1cccnc1</smiles><smiles>O=Cc1ccc2[nH]cc(C=O)c2c1</smiles><smiles>N#C/C=N\C(=O)c1cccnc1</smiles><smiles>[NH3+]C(=O)c1cccnc1</smiles><smiles>COc1cc(C=O)cc(OC)c1OC</smiles><smiles>CCOC(=O)COC(=O)CC</smiles>

FIGURE 1: Synthetic schemes of IMN and TMN.

triazole derivatives [25], and lauric hydrazide derivatives [26] have been reported as anticorrosion substances.

In view of the literature cited above, the present work describes the study of inhibitive behaviour and adsorption mechanism of two nicotinamide derivatives such as $\mathrm{N}$-(1H-Indol-3-yl-methylene)-nicotinamide (IMN) and $\mathrm{N}$ (3,4,5-trimethoxy-benzylidene)-nicotinamide (TMN) on the corrosion of $\mathrm{MS}$ in $0.5 \mathrm{M} \mathrm{HCl}$ using mass loss and electrochemical techniques. The effect of temperature on the dissolution of MS in free and inhibited acid solutions has been studied. Various activation and adsorption thermodynamic parameters were computed. The passive film formed on the metal surface was characterized by FTIR, EDX, and SEM. Further, the inhibition performances of the two derivatives have been compared and discussed.

\section{Experimental Procedure}

2.1. Mild Steel Specimen Preparation. MS specimens used in the present study having the following chemical composition (in wt\%): C 0.051; Mn 0.179; Si 0.006; P 0.005; S 0.023; Cr 0.051; Ni 0.05; Mo 0.013; Ti 0.004; Al 0.103; Cu 0.050; Sn 0.004; B 0.00105; Co 0.017; Nb 0.012; Pb 0.001; and the remainder iron. For all experiments, square type MS specimens of dimension $1 \mathrm{~cm} \times 1 \mathrm{~cm} \times 0.1 \mathrm{~cm}$ were used. The specimens were mechanically well abraded with different grades $\mathrm{SiC}$ (200-600) emery papers, degreased with benzene, washed with triply distilled water, and finally dried. All solvents and chemicals used were of AR grade and used as such. Triply distilled water was used in the preparation of the various concentrations of test solutions.

2.2. Synthesis of Inhibitors. IMN was synthesized by dissolving $0.61 \mathrm{~g}(5 \mathrm{mmol})$ of nicotinamide $\left(\mathrm{C}_{6} \mathrm{H}_{6} \mathrm{~N}_{2} \mathrm{O}\right.$, Mol. Wt. 122.12 ) in $15 \mathrm{~mL}$ of ethanol in a round bottom flask. To this
$0.72 \mathrm{~g}(5 \mathrm{mmol})$ of indole-3-carboxaldehyde $\left(\mathrm{C}_{9} \mathrm{H}_{7} \mathrm{NO}\right.$, Mol. Wt. 145.16) in $15 \mathrm{~mL}$ ethanol was mixed and refluxed for $6 \mathrm{hr}$ at room temperature in the presence of glacial acetic acid, and then the solution was concentrated using rotor vaporizer and kept for drying in vacuum. TMN was synthesized by dissolving $0.61 \mathrm{~g}(5 \mathrm{mmol})$ of nicotinamide in $15 \mathrm{~mL}$ of ethanol in a round bottom flask. To this a $0.98 \mathrm{~g}(5 \mathrm{mmol})$ of 3,4,5-trimethoxybenzaldehyde $\left(\mathrm{C}_{10} \mathrm{H}_{12} \mathrm{O}_{4}\right.$, Mol. Wt. 196.20) dissolved in $15 \mathrm{~mL}$ of ethanol was added and refluxed for $6 \mathrm{hrs}$ with stirring at room temperature in the presence of glacial acetic acid. Then the solution was concentrated using rotor vaporizer and kept for drying in vacuum and the product obtained was collected. The synthetic scheme of IMN and TMN are shown in Figure 1.

The chemical structures of the compounds are characterized by FTIR and ${ }^{1} \mathrm{H}-\mathrm{NMR}$ spectral studies. IMN $\left(\mathrm{C}_{15} \mathrm{H}_{11} \mathrm{~N}_{3} \mathrm{O}\right.$, Mol. Wt. 249.27): yield: $92 \%$, melting range $\left({ }^{\circ} \mathrm{C}\right): 148-150$. FTIR (Nujol, $\left.\mathrm{cm}^{-1}\right): 1462(\mathrm{~N}-\mathrm{H}), 1611(\mathrm{~N}=\mathrm{C})$, $1677(\mathrm{C}=\mathrm{O}) .{ }^{1} \mathrm{H}-\mathrm{NMR}\left(400.15 \mathrm{MHz}, \mathrm{DMSO}-\mathrm{d}_{6}\right) \delta$ ppm: 7.21 $(\mathrm{t}, J=7.20 \mathrm{~Hz}, 1 \mathrm{H}), 7.49(\mathrm{t}, J=7.88 \mathrm{~Hz}, 2 \mathrm{H}), 7.51(\mathrm{~d}$, $J=3.28 \mathrm{~Hz}, 1 \mathrm{H}), 8.08(\mathrm{~d}, J=8.40 \mathrm{~Hz}, 2 \mathrm{H}), 8.18(\mathrm{~s}, 1 \mathrm{H}), 8.20$ $(\mathrm{d}, J=4.00 \mathrm{~Hz}, 1 \mathrm{H}), 8.69(\mathrm{~d}, J=4.44 \mathrm{~Hz}, 1 \mathrm{H}), 9.87(\mathrm{~s}, 1 \mathrm{H})$, $12.10(\mathrm{~s}, 1 \mathrm{H})$. MS, $m / z: 250(M+1)$. Elemental analyses found (calculated) for $\mathrm{C}_{15} \mathrm{H}_{11} \mathrm{~N}_{3} \mathrm{O}$ (\%): C, 72.21 (72.28): $\mathrm{H}, 4.39$ (4.45): N, 16.80 (16.86).

TMN $\left(\mathrm{C}_{16} \mathrm{H}_{16} \mathrm{~N}_{2} \mathrm{O}_{4}\right.$, Mol. Wt. 300.31): yield: 90\%, melting range $\left({ }^{\circ} \mathrm{C}\right)$ : 162-164. FTIR (Nujol, $\mathrm{cm}^{-1}$ ): $1589(\mathrm{~N}=\mathrm{C}), 1701$ $(\mathrm{C}=\mathrm{O}) .{ }^{1} \mathrm{H}-\mathrm{NMR}\left(400.15 \mathrm{MHz}, \mathrm{DMSO}-\mathrm{d}_{6}\right) \delta \mathrm{ppm}: 3.83(\mathrm{~s}$, $9 \mathrm{H}), 6.73(\mathrm{dd}, J=1.73,7.88,2 \mathrm{H}), 7.43(\mathrm{t}, J=7.48 \mathrm{~Hz}$, $1 \mathrm{H}), 8.03(\mathrm{~s}, 1 \mathrm{H}), 8.28(\mathrm{~d}, J=7.80 \mathrm{~Hz}, 2 \mathrm{H}), 8.73(\mathrm{~s}, 1 \mathrm{H})$. MS, $m / z: 301(M+1)$. Elemental analyses found (calculated) for $\mathrm{C}_{16} \mathrm{H}_{16} \mathrm{~N}_{2} \mathrm{O}_{4}$ (\%): C, 63.96 (63.99): $\mathrm{H}, 5.31$ (5.37): $\mathrm{N}$, 9.28 (9.33). Melting range was determined by Veego Melting Point VMP III apparatus. FTIR spectra were recorded using a Jasco FTIR 4100 double beam spectrophotometer. ${ }^{1} \mathrm{H}-\mathrm{NMR}$ 
spectra were recorded on Bruker DRX-500 spectrometer at $400 \mathrm{MHz}$ using DMSO- $d_{6}$ as solvent and TMS as an internal standard. Mass spectral data were obtained by LC/MSD Trap $\mathrm{XCT}$. Elemental analyses were recorded on Vario-MICRO superuser V1.3.2 Elementar.

\section{Methods}

3.1. Mass Loss Measurements. Mass loss measurements were carried out by weighing the prepared cleaned and dried MS specimens before and after immersion in $0.5 \mathrm{M} \mathrm{HCl}$ solutions from one to five hours in the absence and presence of various concentrations of IMN and TMN at different temperatures $\left(30-60^{\circ} \mathrm{C}\right)$. Triplicate experiments were performed in each case and the mean value of the mass loss was noted. From the mass loss data, corrosion rate (CR) in $\mathrm{mg} \mathrm{cm}^{-2} \mathrm{~h}^{-1}$ and inhibition efficiency IE (\%) were calculated using the following equations:

$$
\mathrm{CR}=\frac{\Delta M}{S t},
$$

where $\Delta M$ is the mass loss, " $S$ " is the surface area of the specimen, and " $t$ " is the immersion time.

Consider

$$
\operatorname{IE}(\%)=\frac{(\mathrm{CR})_{a}-(\mathrm{CR})_{p}}{(\mathrm{CR})_{a}} \times 100,
$$

where $(\mathrm{CR})_{a}$ and $(\mathrm{CR})_{p}$ are the corrosion rates in the absence and presence of inhibitor, respectively.

3.2. Potentiodynamic Polarization Measurements. The potentiodynamic polarization studies were carried out with MS specimen as working electrode in $0.5 \mathrm{M} \mathrm{HCl}$ solutions with different inhibitor's concentrations (200-500 ppm) with an exposed area of $1 \mathrm{~cm}^{2}$ and this working area remained precisely fixed throughout the experiment. All studies were made using three electrode cells consisting of MS sample as working electrode (WE), platinum counter electrode (CE), and saturated calomel electrode (SCE) as reference electrode. The temperature of the medium was maintained at $30^{\circ} \mathrm{C}$ using thermostatically controlled water bath. Potentiodynamic polarization studies were carried out using $\mathrm{CH}$-instrument (model CHI660D). Before each experiment, the MS electrode was allowed to corrode freely and its open circuit potential (OCP) was recorded as a function of time upto $30 \mathrm{~min}$. After this time, a steady state OCP corresponding to the corrosion potential $\left(E_{\text {corr }}\right)$ of the working electrode was obtained. The polarization curves were recorded by changing the electrode potential automatically at a scan rate of $0.2 \mathrm{~m} \mathrm{~V} / \mathrm{s}$. The IE (\%) was calculated from corrosion currents determined from the Tafel extrapolation plot method using the following relation:

$$
\operatorname{IE}(\%)=\frac{\left(I_{\text {corr }}\right)_{a}-\left(I_{\text {corr }}\right)_{p}}{\left(I_{\text {corr }}\right)_{a}} \times 100,
$$

where $\left(I_{\text {corr }}\right)_{a}$ and $\left(I_{\text {corr }}\right)_{p}$ are the corrosion current density $\left(\mu \mathrm{Acm}^{-2}\right)$ in the absence and presence of the inhibitor, respectively.
3.3. Electrochemical Impedance Spectroscopy. Electrochemical impedance measurements were carried out in the form of Nyquist plots using the same $\mathrm{CH}$-instrument. The electrochemical impedance spectroscopy (EIS) data were taken in the frequency range $10 \mathrm{kHz}$ to $100 \mathrm{mHz}$. The double layer capacitance $\left(C_{\mathrm{dl}}\right)$ and the polarization resistance $\left(R_{P}\right)$ were determined from Nyquist plots. The percentage inhibition efficiency, IE (\%), was calculated from $R_{P}$ values using the following expression:

$$
\operatorname{IE}(\%)=\frac{1 /\left(R_{P}\right)_{a}-1 /\left(R_{P}\right)_{p}}{1 /\left(R_{P}\right)_{a}} \times 100,
$$

where $\left(R_{P}\right)_{a}$ and $\left(R_{P}\right)_{p}$ are polarization resistances in the absence and presence of inhibitor, respectively.

3.4. FTIR, EDX, and SEM Studies. The surface characterization of uninhibited and inhibited MS specimens were carried out using FTIR, EDX, and SEM studies. The prepared MS specimens were immersed in $0.5 \mathrm{M} \mathrm{HCl}$ in the presence of inhibitors $(500 \mathrm{ppm})$ for a period of $5 \mathrm{hr}$. Then the specimens were taken out and dried. The thin film that adhered on the MS surface was scrapped carefully and its FTIR spectra were recorded. Further, surface morphology was studied by energy dispersive X-ray spectroscopy (EDX) and scanning electron microscope (model JSM-5800) in the absence and the presence of inhibitors.

\section{Results and Discussion}

4.1. Mass Loss Studies. The CR and IE (\%) in the absence and presence of various concentrations (200-500 ppm) of IMN and TMN in $0.5 \mathrm{M} \mathrm{HCl}$ solution and at different temperatures $\left(30-60^{\circ} \mathrm{C}\right)$ were calculated by mass loss experiments, and the data were presented in Table 1 . Investigation of mass loss data revealed the linear variation of mass loss with temperature, concentration, and time in inhibited and uninhibited solution. The mass loss was found to decrease and IE (\%) observed to increase with increase in concentration of nicotinamide derivatives and the maximum inhibition efficiency was found at $500 \mathrm{ppm}$. This observation is also supported by electrochemical studies. After $6 \mathrm{hr}$ of immersion time there is no any appreciable increase in the inhibition efficiency, this is due to desorption of the inhibitor molecules from the MS surface and instability of inhibitor film on the metal surface [27, 28].

The inhibition efficiency of the nicotinamide derivatives was found to depend on the concentration and the nature of the substituents. The increase in concentration of the inhibitors was accompanied by decrease in weight loss and increase in the inhibition efficiency. The inhibition efficiency obtained from mass loss measurements is lower than that for electrochemical experiments, because the mass loss experiment gives average corrosion rates whereas the electrochemical experiments gives instantaneous corrosion rates.

4.2. Effect of Temperature. The effect of temperature on CR and IE (\%) was studied in $0.5 \mathrm{M} \mathrm{HCl}$ in the temperature range of $30-60^{\circ} \mathrm{C}$ in the absence and presence of different 
TABLE 1: CR and IE (\%) obtained from mass loss measurements of $\mathrm{MS}$ in $0.5 \mathrm{M} \mathrm{HCl}$ solution containing various concentrations of IMN and TMNat different temperatures.

\begin{tabular}{|c|c|c|c|c|c|}
\hline \multirow{2}{*}{$T\left({ }^{\circ} \mathrm{C}\right)$} & \multirow{2}{*}{$\begin{array}{c}C \\
(\mathrm{ppm})\end{array}$} & \multicolumn{2}{|c|}{ IMN } & \multicolumn{2}{|c|}{ TMN } \\
\hline & & $\begin{array}{c}\mathrm{CR} \\
\left(\mathrm{mg} \mathrm{cm}^{-2} \mathrm{~h}^{-1}\right)\end{array}$ & IE (\%) & $\begin{array}{c}\mathrm{CR} \\
\left(\mathrm{mg} \mathrm{cm}^{-2} \mathrm{~h}^{-1}\right)\end{array}$ & IE (\%) \\
\hline \multirow{5}{*}{30} & Blank & 0.7200 & - & 0.7200 & - \\
\hline & 200 & 0.2096 & 70.9 & 0.1262 & 82.5 \\
\hline & 300 & 0.1555 & 78.4 & 0.0770 & 89.3 \\
\hline & 400 & 0.1430 & 80.2 & 0.0644 & 91.1 \\
\hline & 500 & 0.1123 & 84.4 & 0.0386 & 94.6 \\
\hline \multirow{5}{*}{40} & Blank & 0.9490 & - & 0.9490 & - \\
\hline & 200 & 0.2820 & 70.3 & 0.1783 & 81.2 \\
\hline & 300 & 0.2412 & 74.6 & 0.1407 & 85.2 \\
\hline & 400 & 0.2008 & 78.8 & 0.1005 & 89.4 \\
\hline & 500 & 0.1570 & 83.5 & 0.0664 & 93.0 \\
\hline \multirow{5}{*}{50} & Blank & 1.1520 & - & 1.1520 & - \\
\hline & 200 & 0.3617 & 68.6 & 0.2357 & 79.5 \\
\hline & 300 & 0.3100 & 73.1 & 0.1832 & 84.1 \\
\hline & 400 & 0.2671 & 76.8 & 0.1436 & 87.5 \\
\hline & 500 & 0.2214 & 80.8 & 0.0945 & 91.8 \\
\hline \multirow{5}{*}{60} & Blank & 1.4350 & - & 1.4350 & - \\
\hline & 200 & 0.4791 & 66.6 & 0.3292 & 77.1 \\
\hline & 300 & 0.3916 & 72.7 & 0.2381 & 83.4 \\
\hline & 400 & 0.3649 & 74.6 & 0.2105 & 85.3 \\
\hline & 500 & 0.2913 & 79.7 & 0.1427 & 90.1 \\
\hline
\end{tabular}

concentrations of inhibitors (Table 1). The inhibition efficiencies were found to decrease with increasing temperature from $30-60^{\circ} \mathrm{C}$. Desorption of inhibitors is aided by increasing temperature. This proves that the inhibition occurs through the adsorption of the inhibitors on the metal surface. The corrosion current density increases with the rise of temperature and markedly pronounced in the absence of inhibitors. The activation parameters for the corrosion process were calculated from the Arrhenius type plot according to the following equation:

$$
\mathrm{CR}=k \exp ^{-E_{a} / R T}
$$

where $E_{a}$ is the apparent activation energy for corrosion process $k$ is the Arrhenius preexponential factor, $T$ is the absolute temperature, and $R$ is the universal gas constant. The values of $E_{a}$ for $\mathrm{MS}$ in $0.5 \mathrm{M} \mathrm{HCl}$ without and with various concentrations of inhibitors are obtained from the slopes of the plots of $\log C R$ versus $1 / T$ (Figure 2 ) and are shown in Table 2. $E_{a}$ values for inhibited systems are higher than those for the uninhibited systems suggest that dissolution of MS is slow [29]. Further, as the concentration of the inhibitors increases the values of $E_{a}$ also increases. This means the presence of the inhibitors induces an energy barrier for corrosion reaction and the barrier increases with increasing concentration. At higher temperatures, there is an appreciable decrease in the adsorption of the inhibitors on the metal surface and a corresponding rise in the corrosion rate occurred.

Alternative Arrhenius plots of $\log \mathrm{CR} / T$ versus $1 / T$ (Figure 3) for MS dissolution in $\mathrm{HCl}$ medium in the absence and presence of different concentrations of IMN and TMN were used to calculate the values of activation thermodynamic parameters such as enthalpy of activation $\left(\Delta H_{a}\right)$ and entropy of activation $\left(\Delta S_{a}\right)$ using the following relation:

$$
\mathrm{CR}=\frac{R T}{N h} \exp \left(\frac{\Delta S_{a}}{R}\right) \exp \left(\frac{-\Delta H_{a}}{\mathrm{RT}}\right),
$$

where $R$ is the universal gas constant, $T$ is the absolute temperature, $N$ is the Avogadro's number, and $h$ is Planks constant. The values of $\Delta H_{a}$ and $\Delta S_{a}$ were obtained from the slope and intercept of the above plot and presented in Table 2. The obtained $\Delta H_{a}$ values are in good agreement with the calculated values from the following equation:

$$
\Delta H_{a}=E_{a}-R T \text {. }
$$

The positive shift of enthalpy of activation $\left(\Delta H_{a}\right)$ with different inhibitors concentration reflects that the process of adsorption of the inhibitors on the MS surface is an endothermic process [30], and the negative values of entropy of activation $\left(\Delta S_{a}\right)$ represents association rather than dissociation of inhibitors indicating the decrease of system disorder due to the adsorption of inhibitor molecules on the MS surface [31-33]. The values of $\Delta S_{a}$ are higher for inhibited solutions than those for the uninhibited solution reflecting an increase in randomness on going from reactants to the activated complex. The increase in values of $\Delta S_{a}$ by the adsorption of inhibitor molecules on the MS surface could be regarded as quasisubstitution between the inhibitors molecules in the aqueous phase and water molecules on electrode surface [34]. In such condition, the adsorption of inhibitor molecules follow desorption of water molecules from the electrode surface and hence decrease the electrical capacity of MS.

4.3. Adsorption Isotherm. The efficiency of a corrosion inhibitor mainly depends on its adsorption ability on the metal surface. So, it is necessary to know the mechanism of adsorption and the adsorption isotherm that can give valuable information on the interaction of inhibitor and metal surface. The surface protection of MS depends upon how the inhibitor molecule will adsorbed on the metal surface and also ionization and polarization of molecules [35]. The degree of surface coverage $(\theta)$ as function of concentration (C) of the inhibitor was studied graphically by fitting it to various adsorption isotherms to find the best adsorption isotherm. Langmuir adsorption isotherm was found to be the best description for all the studied inhibitors on MS in $0.5 \mathrm{M} \mathrm{HCl}$ medium. According to this adsorption isotherm, $\theta$ is related to the inhibitor concentration, $C$, and adsorption equilibrium constant $K_{\text {ads }}$ through the following expression:

$$
\frac{C}{\theta}=\frac{1}{K_{\mathrm{ads}}}+C .
$$


TABLE 2: Values of activation parameters for MS in $0.5 \mathrm{M} \mathrm{HCl}$ medium in the absence and presence of various concentrations IMN and TMN.

\begin{tabular}{lccccc}
\hline Inhibitor & $\begin{array}{c}\mathrm{C} \\
(\mathrm{ppm})\end{array}$ & $\begin{array}{c}E_{a} \\
\left(\mathrm{~kJ} \mathrm{~mol}^{-1}\right)\end{array}$ & $\begin{array}{c}\Delta H_{a} \\
\left(\mathrm{~kJ} \mathrm{~mol}^{-1}\right)\end{array}$ & $\begin{array}{c}\Delta H_{a}=E_{a}-R T \\
\left(\mathrm{~kJ} \mathrm{~mol}^{-1}\right)\end{array}$ & $\begin{array}{c}\Delta S_{a} \\
\left(\mathrm{~J} \mathrm{~mol}^{-1} \mathrm{~K}^{-1}\right)\end{array}$ \\
\hline Blank & 0 & 19.0 & 16.4 & 20.4 & -197.6 \\
\hline \multirow{3}{*}{ IMN } & 200 & 22.9 & 20.2 & 22.9 & -191.3 \\
& 300 & 25.4 & 22.8 & 23.4 & -184.9 \\
& 400 & 25.9 & 23.3 & 24.4 & -184.3 \\
TMN & 500 & 26.9 & 24.2 & 23.92 & -183.2 \\
& 200 & 26.4 & 23.8 & 30.23 & -172.9 \\
& 300 & 30.8 & 30.2 & 33.38 & -162.1 \\
\hline
\end{tabular}

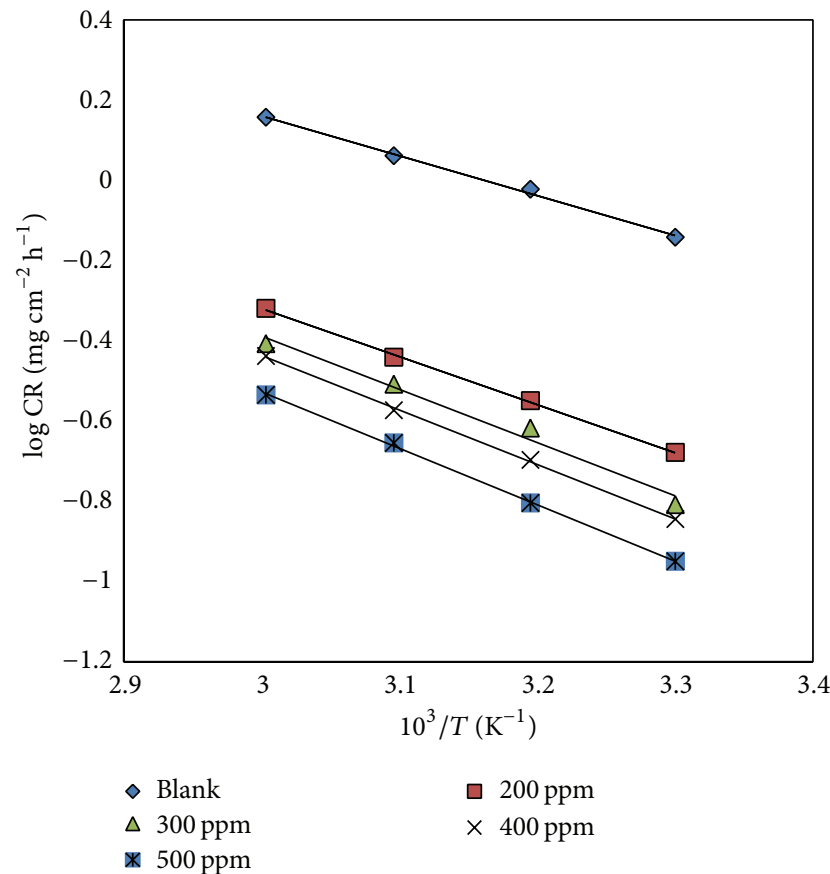

(a)

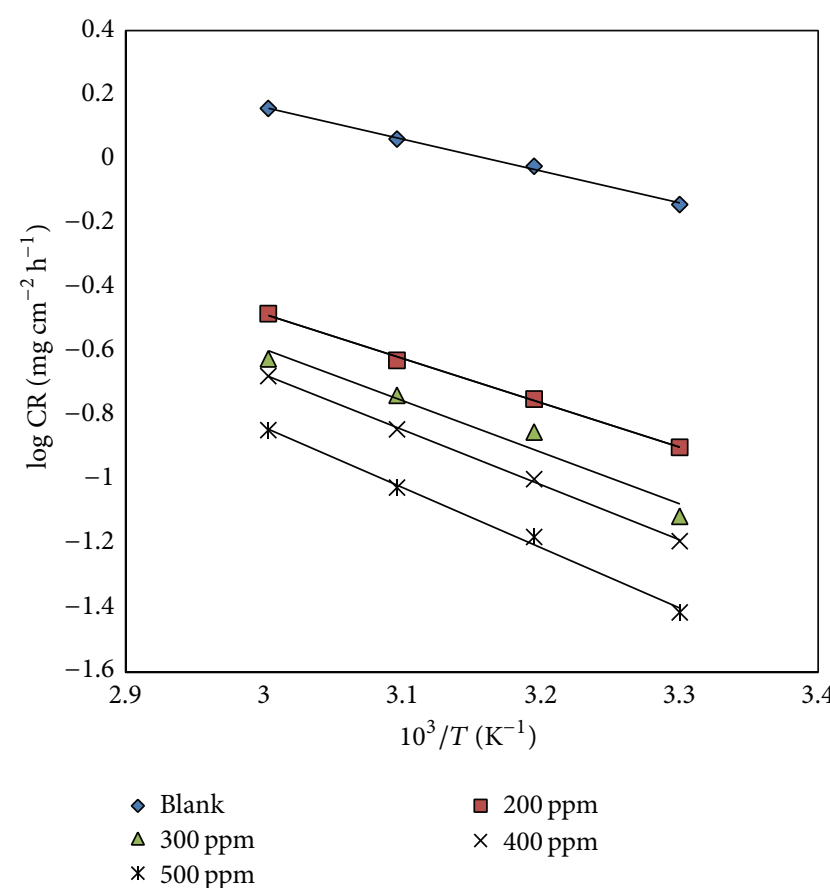

(b)

Figure 2: Plot of $\log$ CR versus $1 / T$ for (a) IMN and (b) TMN.

The surface coverage was tested graphically by fitting a suitable adsorption isotherm. In the present case, the plots of $C / \theta$ versus $C$ (Figure 4 ) yields straight lines with the linear correlation coefficient $\left(R^{2}\right)$ values close to unity, which suggests that the adsorption of IMN and TMN in $0.5 \mathrm{M}$ $\mathrm{HCl}$ medium on MS surface obeys the Langmuir adsorption isotherm. The slope ranges of these lines are 1.047-1.105 (IMN) and $0.960-0.996$ (TMN) in the temperature range of $30-60^{\circ} \mathrm{C}$, respectively, suggesting that the adsorbed molecules form monolayer on the MS surface and there is no interaction among the adsorbed inhibitor molecules. The free energy of adsorption was calculated using the following relation:

$$
\Delta G_{\mathrm{ads}}^{\circ}=-2.303 R T \log 55.5 K_{\mathrm{ads}}
$$

where $R$ is the universal gas constant, $T$ is the absolute temperature, $K_{\text {ads }}$ is the equilibrium constant for adsorptiondesorption process, and 55.5 is the molar concentration of water in solution $\left(\mathrm{mol} \mathrm{L}^{-1}\right)$. The other adsorption thermodynamic parameters such as enthalpy of adsorption $\left(\Delta H_{\mathrm{ads}}^{\circ}\right)$ and entropy of adsorption $\left(\Delta S_{\text {ads }}^{\circ}\right)$ were obtained from the slope and intercept of the plot of $\ln K_{\mathrm{ads}}$ versus $1 / T$ (Figure 5) using

$$
\log K_{\mathrm{ads}}=\frac{1}{2.303}\left(-\frac{\Delta H_{\mathrm{ads}}^{\circ}}{R T}\right)+\left(\frac{\Delta S_{\mathrm{ads}}^{\circ}}{R}\right) .
$$

The calculated values of $K_{\mathrm{ads}}, \Delta H_{\mathrm{ads}}^{\circ}, \Delta G_{\mathrm{ads}}^{\circ}$, and $\Delta S_{\text {ads }}^{\circ}$ over the temperature range $30-60^{\circ} \mathrm{C}$ are recorded in Table 3 . Lagrenée et al. have reported that the higher the $K_{\text {ads }}$ values, the stronger and more stable adsorbed layer is forming which results in the higher inhibition efficiency [36]. The 


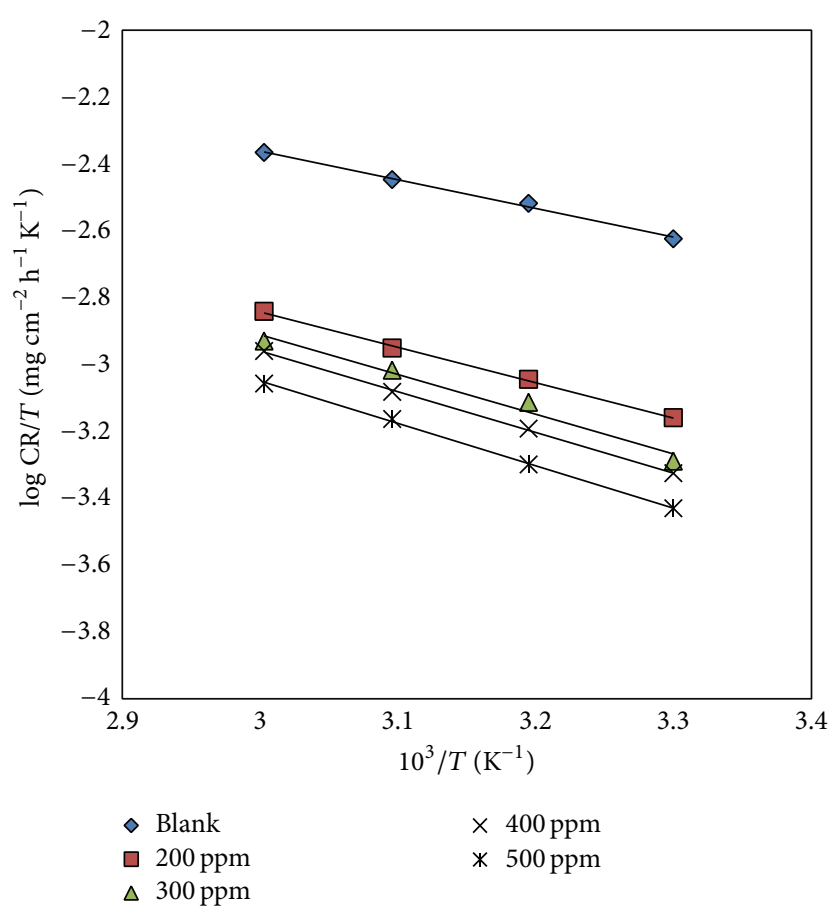

(a)

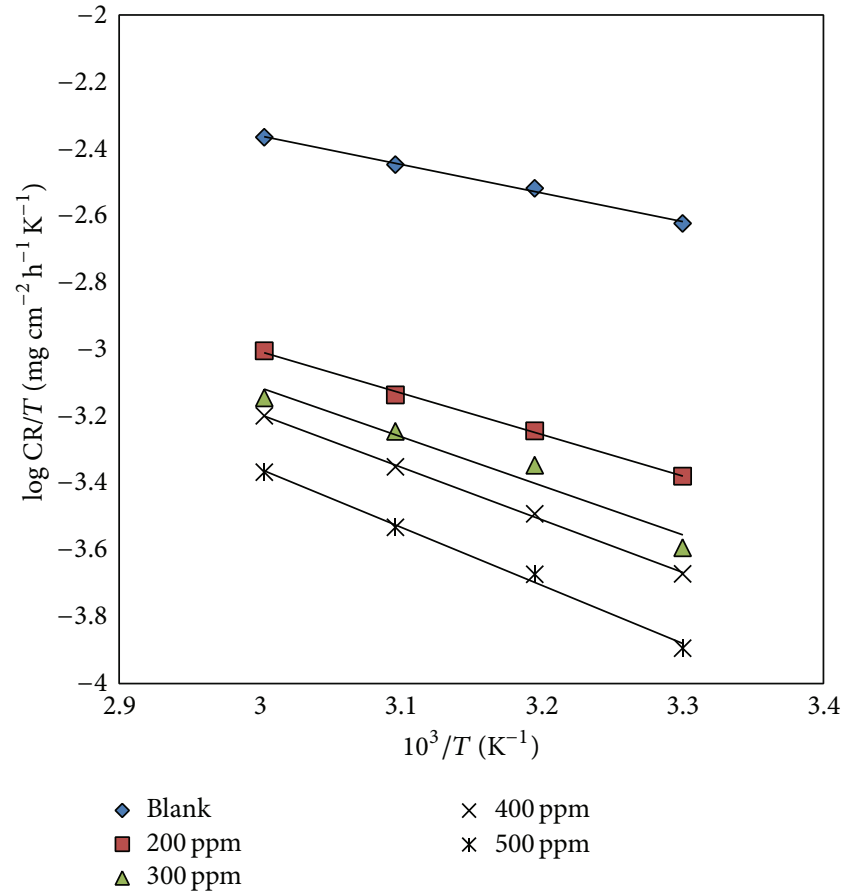

(b)

FIGURE 3: Alternative Arrhenius plots for MS dissolution in $0.5 \mathrm{M} \mathrm{HCl}$ medium in the absence and presence of (a) IMN and (b) TMN.

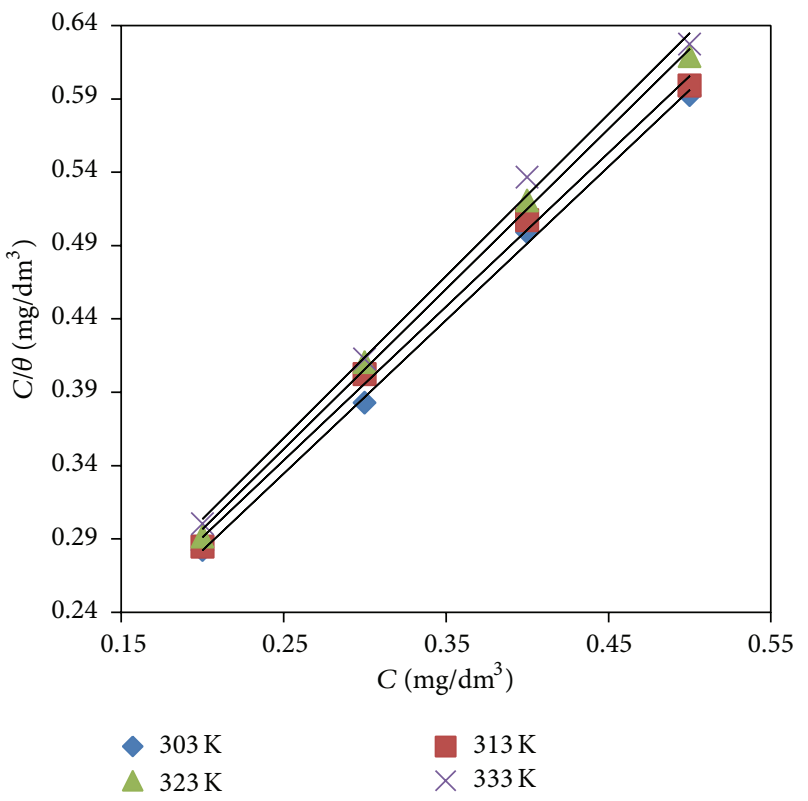

(a)

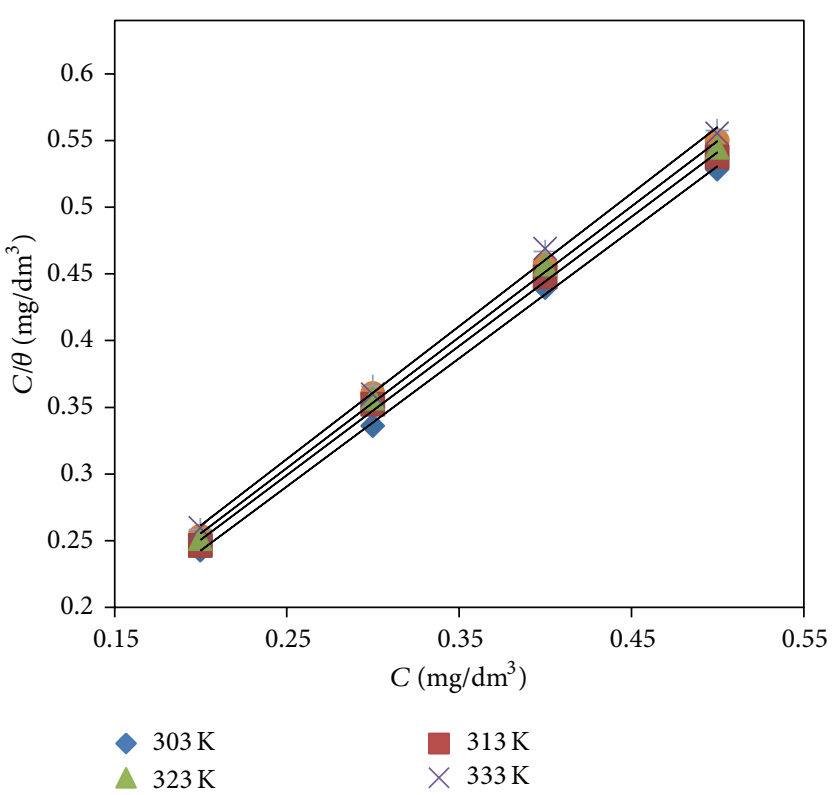

(b)

Figure 4: Langmuir's adsorption isotherm plots for the adsorption of (a) IMN and (b) TMN in $0.5 \mathrm{M} \mathrm{HCl}$ on $\mathrm{MS}$ surface at different temperatures.

negative values of $\Delta G_{\text {ads }}^{\circ}$ indicate the spontaneous adsorption of inhibitor on the MS surface [37]. The values of $\Delta G_{\text {ads }}^{\circ}$ are associated with water adsorption/desorption equilibrium which forms an important part in the overall free energy changes. In the present study, $\Delta G_{\text {ads }}^{\circ}$ values for IMN and TMN are found to be in the range -34.15 to -37.17 and -35.07 to $-37.94 \mathrm{~kJ} \mathrm{~mol}^{-1}$ in the temperature range of $30-60^{\circ} \mathrm{C}$, respectively, which indicates charge transfer or electron sharing from the inhibitor molecules to the metal surface to form a coordinate type of bond $[38,39]$. The calculated standard 
TABLE 3: Thermodynamic parameters for adsorption of IMN and TMNon MS in $0.5 \mathrm{M} \mathrm{HCl}$ at different temperatures.

\begin{tabular}{|c|c|c|c|c|c|c|c|}
\hline Inhibitor & $\begin{array}{c}T \\
\left({ }^{\circ} \mathrm{C}\right) \\
\end{array}$ & $R^{2}$ & Slope & $\begin{array}{c}K_{\mathrm{ads}} \\
\left(\mathrm{L} \mathrm{mol}^{-1}\right)\end{array}$ & $\begin{array}{c}-\Delta G_{\text {ads }}^{\circ} \\
\left(\mathrm{kJ} \mathrm{mol}^{-1}\right)\end{array}$ & $\begin{array}{c}\Delta H_{\mathrm{ads}}^{\circ} \\
\left(\mathrm{kJ} \mathrm{mol}^{-1}\right)\end{array}$ & $\begin{array}{c}\Delta S_{\mathrm{ads}}^{\circ} \\
\left(\mathrm{J} \mathrm{mol}^{-1} \mathrm{~K}^{-1}\right) \\
\end{array}$ \\
\hline \multirow{4}{*}{ IMN } & 30 & 0.998 & 1.047 & 13888 & -34.2 & \multirow{4}{*}{0.405} & \multirow{4}{*}{8.18} \\
\hline & 40 & 0.997 & 1.048 & 12820 & -35.1 & & \\
\hline & 50 & 0.998 & 1.092 & 12345 & -36.1 & & \\
\hline & 60 & 0.996 & 1.105 & 12195 & -37.2 & & \\
\hline \multirow{4}{*}{ TMN } & 30 & 0.999 & 0.960 & 20000 & -35.1 & \multirow{4}{*}{0.653} & \multirow{4}{*}{7.72} \\
\hline & 40 & 0.998 & 0.969 & 17857 & -35.9 & & \\
\hline & 50 & 0.998 & 0.980 & 16949 & -36.9 & & \\
\hline & 60 & 0.998 & 0.996 & 16129 & -37.9 & & \\
\hline
\end{tabular}

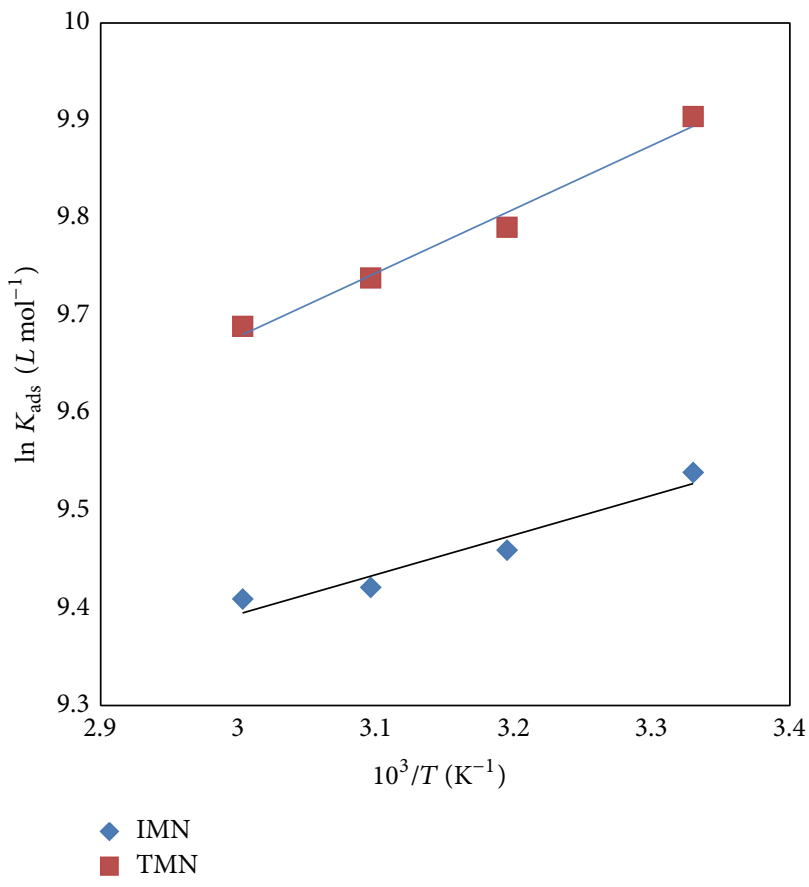

FIgure 5: Plot of $\ln K_{\text {ads }}$ versus $1 / T$ for (a) IMN and (b) TMN.

free energy of adsorption values was nearer to $-40 \mathrm{~kJ} \mathrm{~mol}^{-1}$ indicating that the adsorption is more physisorption than chemisorption adsorption $[40,41]$.

4.4. IR Spectral Studies. FTIR spectra were recorded to understand the interaction of inhibitor molecules with the metal surface. Figures 6(a) and 7(a) show the IR spectra of pure IMN and TMN. Figures 6(b) and 7(b) represent the IR spectra of the scrapped samples obtained from the metal surfaces after corrosion experiments. It was found that peaks in the spectrum of pure compounds were changed in the spectrum of scrapped samples. The azomethine group stretching frequency for pure IMN and TMN were found to be at 1611 and $1589 \mathrm{~cm}^{-1}$, and carbonyl stretching frequency were observed at 1677 and $1701 \mathrm{~cm}^{-1}$, respectively. In the IR spectra of scrapped samples, the stretching frequencies of the azomethine group were found to disappear in both cases and carbonyl group was found to disappear in IMN and found to
TABLE 4: Polarization parameters and corresponding inhibition efficiency (IE) for the corrosion of the MS in $0.5 \mathrm{M} \mathrm{HCl}$ without and with various concentrations of IMN and TMNat $30^{\circ} \mathrm{C}$.

\begin{tabular}{lcccc}
\hline Inhibitor & $\begin{array}{c}C \\
(\mathrm{ppm})\end{array}$ & $\begin{array}{c}-E_{\text {corr }} \\
(\mathrm{mV})\end{array}$ & $\begin{array}{c}i_{\text {corr }} \\
\left(\mu \mathrm{A} \mathrm{cm}^{-2}\right)\end{array}$ & $\begin{array}{c}\text { IE } \\
(\%)\end{array}$ \\
\hline Blank & 0 & 613 & 1061 & - \\
\hline \multirow{4}{*}{ IMN } & 200 & 605 & 293.8 & 72.3 \\
& 300 & 592 & 230.1 & 78.3 \\
& 400 & 586 & 162.4 & 84.7 \\
& 500 & 511 & 160.5 & 84.9 \\
\hline \multirow{3}{*}{ TMN } & 200 & 531 & 187.1 & 82.4 \\
& 300 & 522 & 121.2 & 88.6 \\
& 400 & 515 & 86.49 & 91.8 \\
& 500 & 503 & 56.89 & 94.6 \\
\hline
\end{tabular}

be shifted to $1663 \mathrm{~cm}^{-1}$ in case of TMN. These observations confirm that the azomethine group and carbonyl group of IMN and TMN are involved in the complex formation with the metal.

4.5. Potentiodynamic Polarization Studies. Polarization measurements have been carried out in order to gain knowledge regarding the kinetics of anodic and cathodic reactions. The obtained polarization curves for $\mathrm{MS}$ in $0.5 \mathrm{M} \mathrm{HCl}$ in the absence and presence of different concentrations of TMN and IMN at $30^{\circ} \mathrm{C}$ are shown in Figure 8. Tafel extrapolation plots showed that the addition of inhibitors hindered the acid attack on the MS electrode. The addition of inhibitors reduces both anodic and cathodic current densities indicating that these inhibitors exhibit cathodic and anodic inhibition effects; hence, they are relatively mixed type of inhibitors $[42,43]$.

The lower values of corrosion current densities facilitates slow electron transfer in the redox process; therefore, the rate of corrosion reaction becomes slower. Usually a low current density and long anodization time present a very good protection against corrosion due to the diminution of the porosity of the anodic films formed. Inspection of data in Table 4 clearly shows that as the concentration of the inhibitors increases there is a gradual decrease in the values of the corrosion potential and corrosion current. The values associated with electrochemical polarization parameters such 


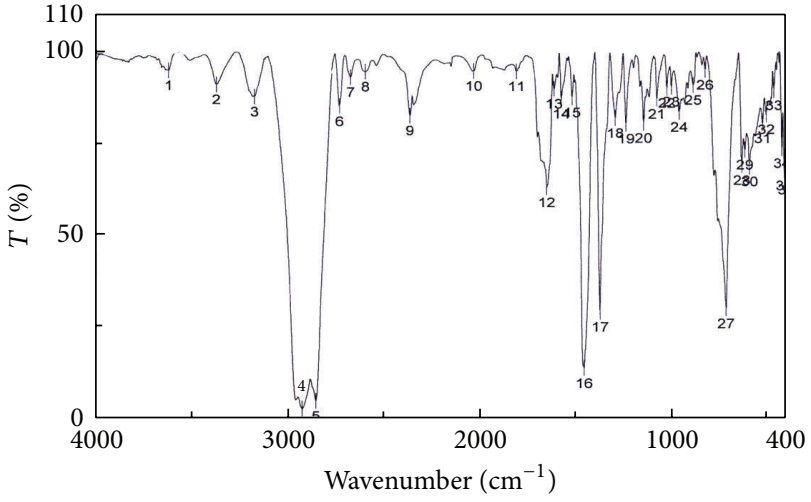

(a)

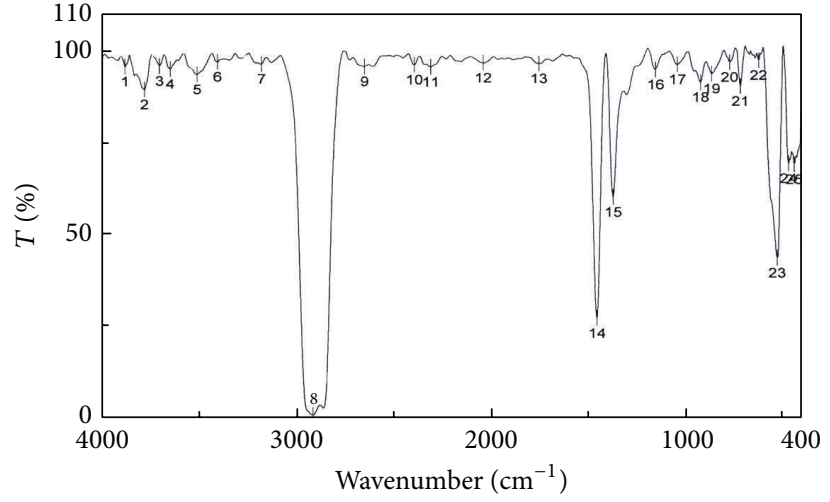

(b)

FIGURE 6: FTIR spectra of (a) IMN and (b) scratched MS surface adsorbed IMN film.

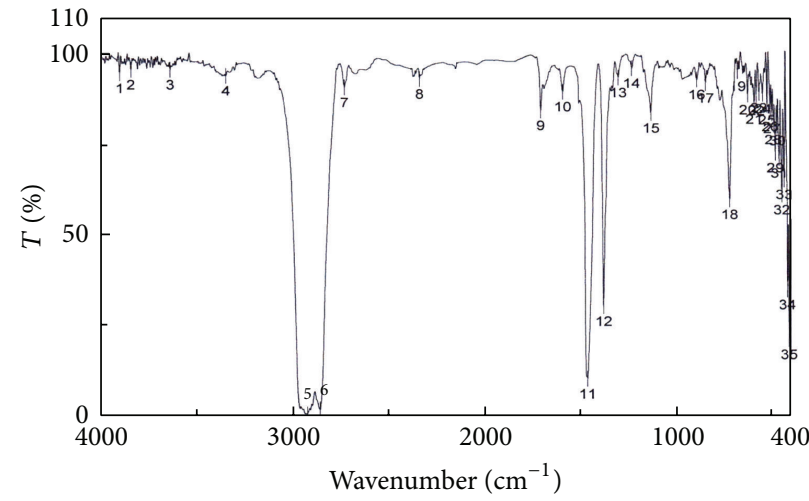

(a)

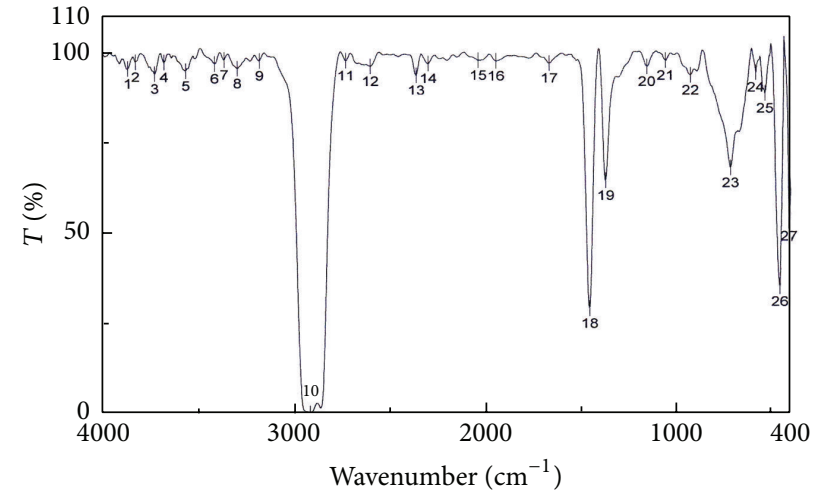

(b)

FIGURE 7: FTIR spectra of (a) TMN and (b) scratched MS surface adsorbed TMN film.
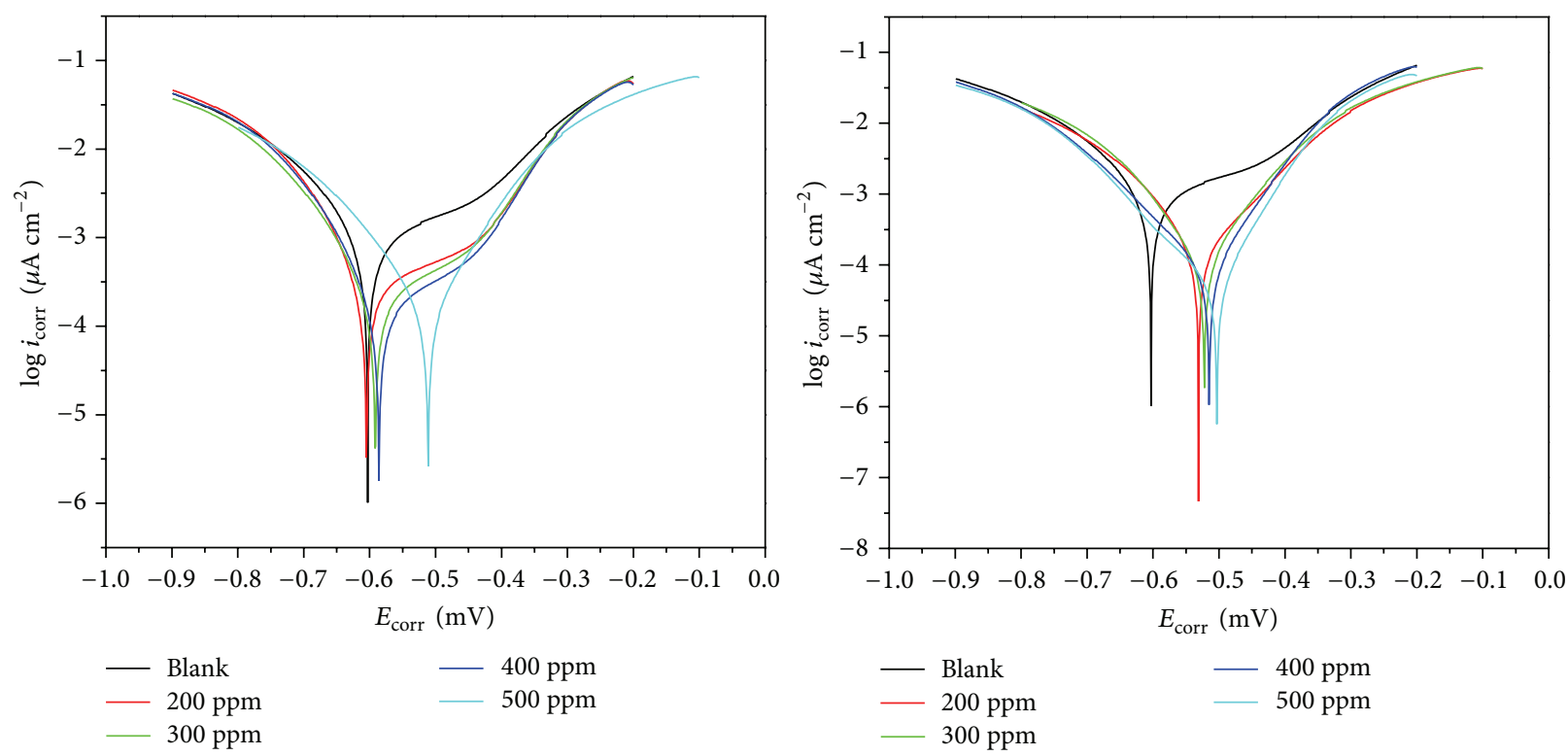

FIgURE 8: Polarization curves of MS in $0.5 \mathrm{M} \mathrm{HCl}$ in the presence of different concentrations of IMN and TMN. 

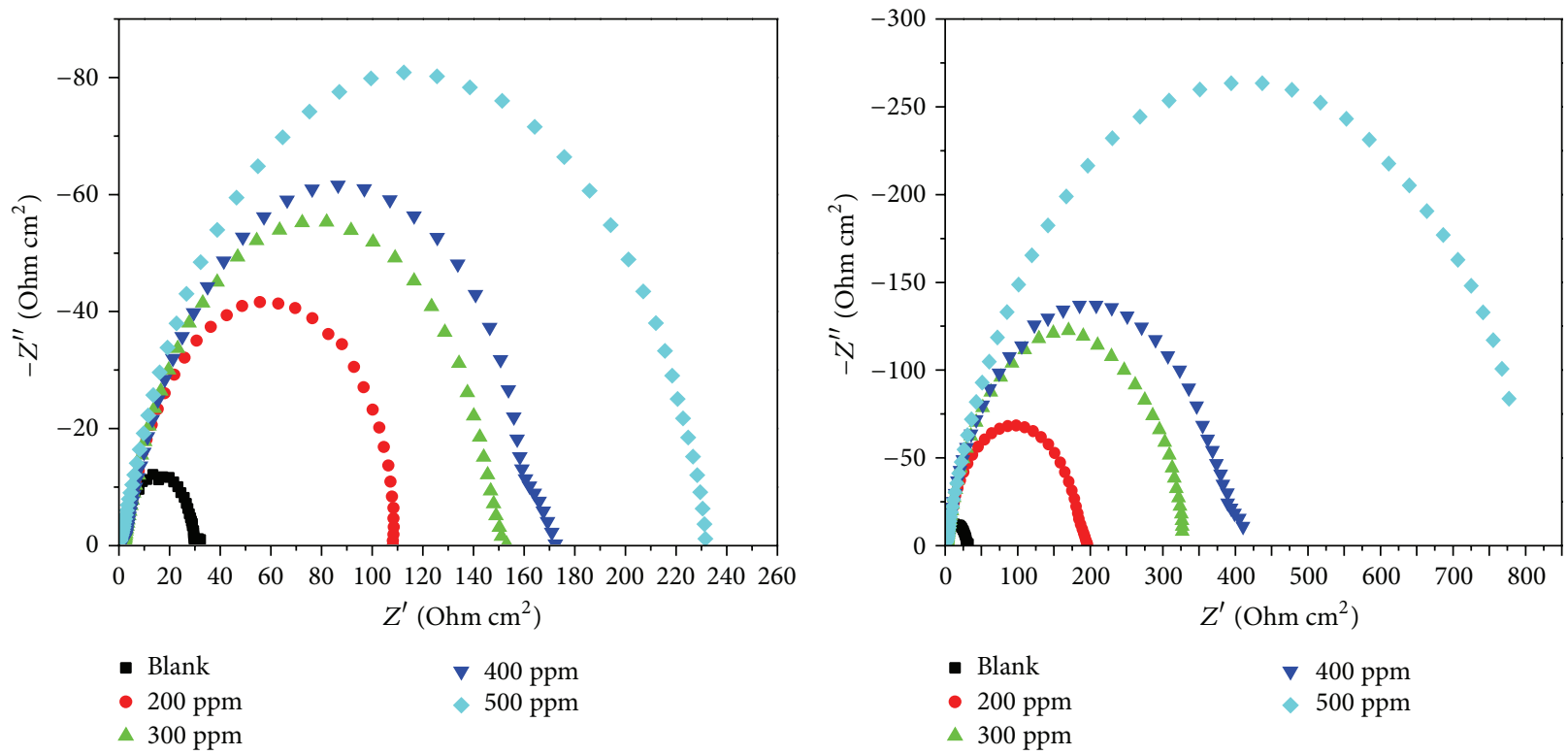

FIGURE 9: Nyquist plots for MS in $0.5 \mathrm{M} \mathrm{HCl}$ in the presence of different concentrations of IMN and TMN.

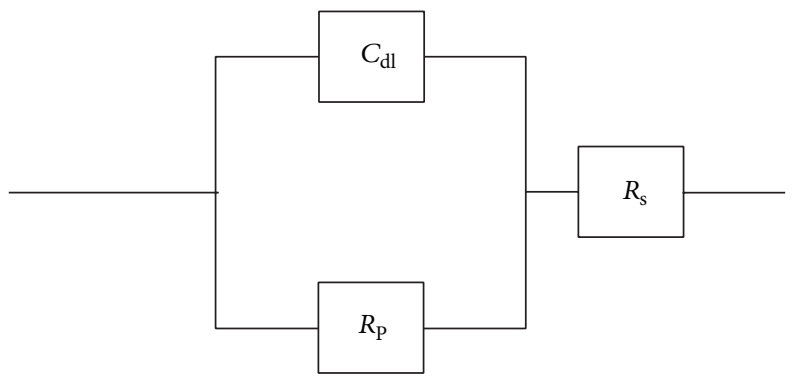

FIGURE 10: Equivalent circuit used to fit the impedance spectra.

as corrosion current density $\left(i_{\text {corr }}\right)$, corrosion potential $\left(E_{\text {corr }}\right)$, corrosion rate, and IE $(\%)$ were determined from the polarization plots as given in Table 4 . The values of corrosion current densities were obtained by extrapolating the currentpotential lines to the corresponding corrosion potentials. It is evident that IE (\%) increases with inhibitors concentration, and protection action of IMN and TMN can be attributed to the electron density of the azomethine $(-\mathrm{C}=\mathrm{N}-)$ group and this electron density varies with the substituents in the inhibitor molecules. The imine nitrogen can donate the lone pair of electrons to the metal surface more easily and hence reduce the corrosion rate. The IE (\%) of the TMN is higher than that of IMN, which can probably be explained on the basis of the additional functional groups and also the nature of the hetero atoms in the TMN.

4.6. Electrochemical Impedance Spectroscopy. The Nyquist plots for MS in $0.5 \mathrm{M} \mathrm{HCl}$ solution with and without different concentrations of IMN and TMN are shown in Figure 9. The Nyquist plots were regarded as one part of a semicircle mostly referred to as frequency dispersion which could be attributed to different physical phenomenon such as roughness, heterogeneities, impurities, grain boundaries, and distribution of
TABLE 5: Impedance parameters for the corrosion of MS in $0.5 \mathrm{M} \mathrm{HCl}$ in the absence and presence of different concentrations of IMN and TMN.

\begin{tabular}{lcccc}
\hline Inhibitor & $\begin{array}{c}C \\
(\mathrm{ppm})\end{array}$ & $\begin{array}{c}R_{p} \\
\left(\Omega \mathrm{cm}^{2}\right)\end{array}$ & $\begin{array}{c}C_{\mathrm{dl}} \\
\left(\mu \mathrm{F} \mathrm{cm}^{-2}\right)\end{array}$ & $\begin{array}{c}\mathrm{IE} \\
(\%)\end{array}$ \\
\hline Blank & 0 & 27.81 & 320.2 & - \\
\hline \multirow{3}{*}{ IMN } & 200 & 95.75 & 102.4 & 71.0 \\
& 300 & 128.4 & 91.07 & 78.3 \\
& 400 & 140.8 & 77.99 & 80.2 \\
& 500 & 181.5 & 61.45 & 84.7 \\
\hline \multirow{3}{*}{ TMN } & 200 & 160.0 & 81.34 & 82.6 \\
& 300 & 271.1 & 67.61 & 89.7 \\
& 400 & 316.1 & 48.73 & 91.2 \\
& 500 & 536.0 & 41.43 & 94.8 \\
\hline
\end{tabular}

the surface active sites [44]. The electrochemical impedance parameters derived from the Nyquist plots and IE (\%) are listed in Table 5. From the plots it is clear that the impedance response of MS in uninhibited acid solution has significantly changed after the addition of inhibitors to the 


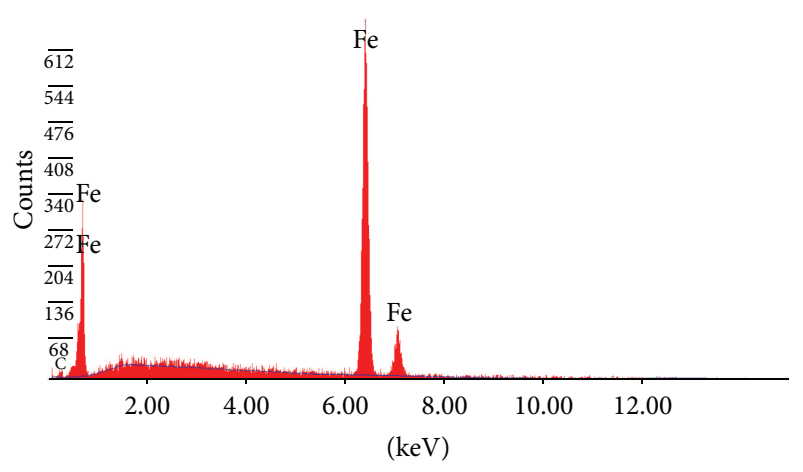

(a)

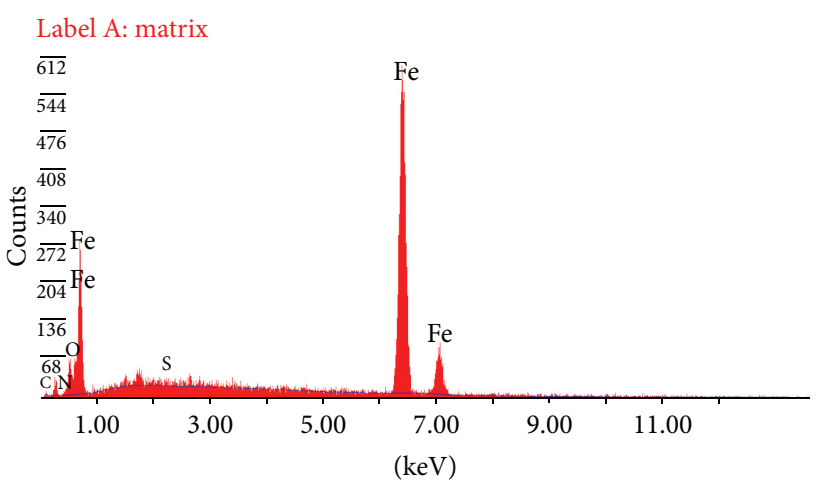

(b)

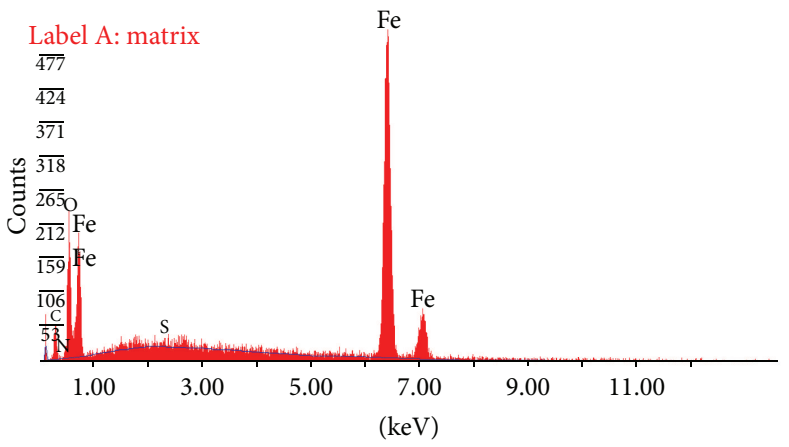

(c)

FIGURE 11: EDX images of (a) abraded MS surface, (b) MS in 500 ppm IMN, and (c) MS in 500 ppm TMN.

corrosive solution. This indicates that the impedance of the inhibited metal has increased with increasing concentration of inhibitors. The measured impedance data were based upon the equivalent circuit given in Figure 10, consists of constant double layer capacitance $\left(C_{\mathrm{dl}}\right)$ in parallel with charge transfer resistance $\left(R_{P}\right)$ which is in series with solution resistance $\left(R_{s}\right)$.

The value of $R_{P}$ is a measure of electron transfer across the surface and inversely proportional to the corrosion rate. It was clear that $R_{P}$ values in the absence of the inhibitors were always lower than those in the presence of the inhibitors. The increase in the $R_{P}$ values in the presence of different concentrations of IMN and TMN indicate reduction in the MS corrosion rate with the formation of adsorbed protective film on the metal-solution interface $[45,46]$. When the concentration was raised from 200 to $500 \mathrm{ppm}$, there was a gradual increase in the diameter of each semicircle of the Nyquist plot reflecting increasing $R_{P}$ values from $27.81 \Omega \mathrm{cm}^{2}$ to $181.5 \Omega \mathrm{cm}^{2}$ and $536.0 \Omega \mathrm{cm}^{2}$ for IMN and TMN, respectively, which indicates the adsorption of inhibitor molecules on the metal surface.

As the adsorption of the inhibitors at the metal-solution interface increases, there is a gradual decrease in the double layer capacitance $\left(C_{\mathrm{dl}}\right)$ and corrosion current $\left(i_{\text {corr }}\right)$ values indicating decrease in local dielectric constant of the electrical double layer [47-49]. The inhibitor decreases the $C_{\mathrm{dl}}$ values by replacing water molecules present at the electrode surface [50]. It was clear that as the immersion time increases the $R_{P}$ values increases and $C_{\mathrm{dl}}$ values decreases which indicate the higher protection efficiency as a result of slow adsorption of these inhibitor molecules on to the surface of MS. However, when the immersion time is further enhanced, a sudden decrease in $R_{P}$ values and increase in $C_{\mathrm{dl}}$ values were observed. This behaviour can be due to the instability of the passive film or desorption of the inhibitor molecules.

4.7. Mechanism of Inhibition. The inhibition effect of nicotinamide derivatives towards the corrosion of MS in $0.5 \mathrm{M}$ $\mathrm{HCl}$ solution may be attributed to the adsorption of these compounds at the metal-solution interface. The adsorption of inhibitor is influenced by the nature of the metal, chemical structure of inhibitors, type of aggressive electrolyte, temperature, and the morphology of MS [51,52]. The values of inhibition efficiency depend essentially on the electron density at the active centre of the inhibitor molecule. Chemisorption of these inhibitors arises from the donor-acceptor interactions between the free electron pairs of hetero atoms and $\pi$ electrons of multiple bonds as well as phenyl group and vacant d-orbitals of iron $[53,54]$.

In the case of IMN, the inhibition effect is due to the interaction of $\pi$-electrons of phenyl and pyridine rings as well as the presence of electron donor groups $(\mathrm{N}, \mathrm{O}$ and $\mathrm{C}=\mathrm{N})$ through which it forms bonds with MS. In the similar way the inhibition effect of TMN is due to $\pi$-electrons of phenyl and pyridine rings, presence of $\mathrm{N}, \mathrm{O}, \mathrm{C}=\mathrm{N}$, and $-\mathrm{OCH}_{3}$, through which the inhibitors adsorb on the MS surface forming insoluble, stable, and uniform thin film. The highest inhibition 


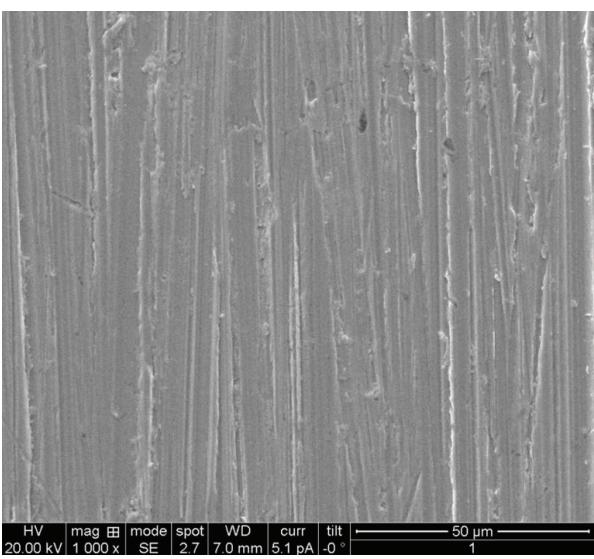

(a)

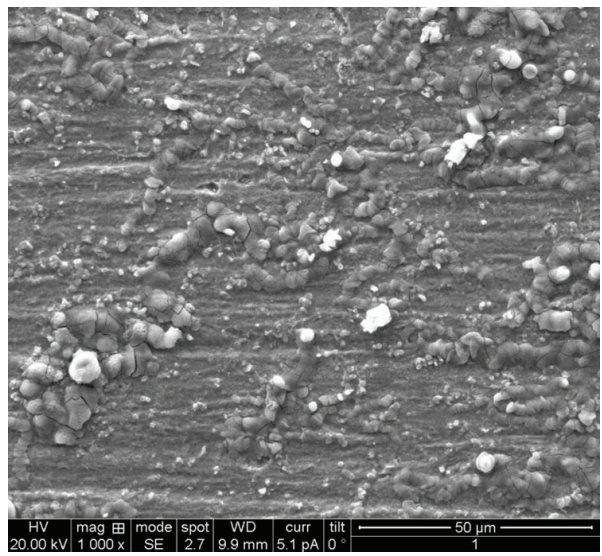

(c)

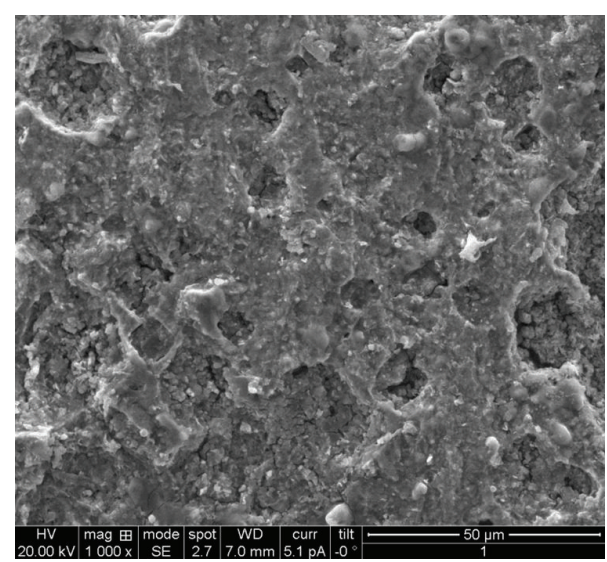

(b)

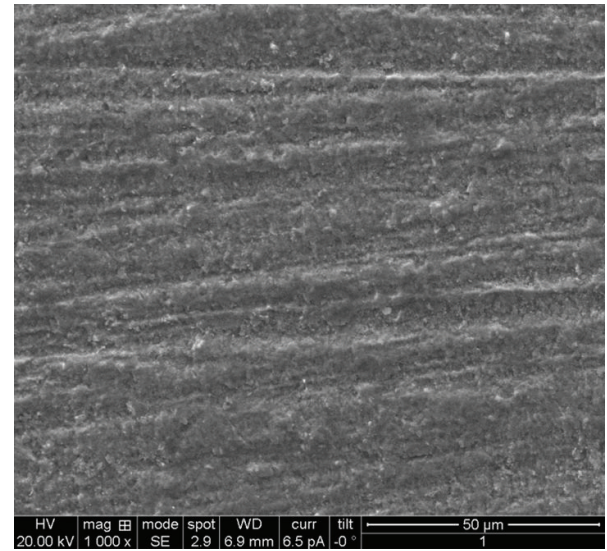

(d)

FIgURE 12: SEM images of (a) abraded MS surface, (b) MS in $0.5 \mathrm{M} \mathrm{HCl}$, (c) MS in 500 ppm IMN, and (d) MS in 500 ppm TMN.

efficiency of TMN is due to the presence of electron donating three methoxy groups adjacent to the phenyl ring, which provides a high electron density and it was found that IE\% increases with electron density.

4.8. EDX Analysis. EDX spectra were used to determine the elements present on MS surface before and after exposure to the inhibitor solution. The results are displayed in Figure 11. Figure 11(a) is the EDX spectrum of abraded MS sample and it is clear that the peak of oxygen is absent which confirm the absence of air formed oxide film. However, for inhibited solutions (Figures 11(b) and 11(c)) the presence of additional lines is a characteristics for the existence of $\mathrm{N}$ and $\mathrm{O}$ in the EDX spectra. These data showed that the $\mathrm{N}$ and $\mathrm{O}$ atom of inhibitors are involved in formation of bonds with the MS electrode surface. These results confirm those obtained from IR and SEM measurements.

4.9. SEM Analysis. The surface morphology of MS due to corrosion process was confirmed by the SEM images of the abraded and corroded MS surface in the absence and presence of inhibitors (Figures 12(a)-12(d)). Figure 12(a) represents the SEM image for abraded MS surface. Figure 12(b) is the SEM image of MS surface in $0.5 \mathrm{M} \mathrm{HCl}$ without inhibitor.
It was found that the corroded MS surface contains large number of pits. However, SEM images of MS surface in the presence of inhibitors were observed to be smoother than that of MS surface in $0.5 \mathrm{M} \mathrm{HCl}$ alone (Figures 12(c) and 12(d)). These observations reveal that, the inhibitors form protective layer on the MS surface, which prevents the attack of acid as well as the dissolution of MS by forming surface adsorbed layer and thereby reducing the corrosion rate.

\section{Conclusions}

(i) The synthesized nicotinamide derivatives showed good inhibition efficiency for the corrosion of MS in $0.5 \mathrm{M} \mathrm{HCl}$ solutions and the inhibition efficiency was found to increase with increasing concentration of the inhibitors.

(ii) Mass loss and electrochemical measurements are in good agreement with each other and the inhibition efficiency of TMN is higher than IMN.

(iii) Langmuir adsorption isotherm model was employed to determine the equilibrium of adsorption for inhibiting process in both inhibitors. 
(iv) Differences in inhibition efficiency between IMN and TMN are correlated with their chemical structures.

(v) The passive film formed on the metal surface was characterized by FTIR, EDX, and SEM.

\section{Conflict of Interests}

The authors declare that there is no conflict of interests regarding the publication of this paper.

\section{Acknowledgment}

One of the authors M. P. Chakravarthy is grateful to the University of Mysore, Mysore, for awarding SRF to carry out the research work.

\section{References}

[1] A. M. Fekry and R. R. Mohamed, "Acetyl thiourea chitosan as an eco-friendly inhibitor for mild steel in sulphuric acid medium," Electrochimica Acta, vol. 55, no. 6, pp. 1933-1939, 2010.

[2] H.-L. Wang, R.-B. Liu, and J. Xin, "Inhibiting effects of some mercapto-triazole derivatives on the corrosion of mild steel in $1.0 \mathrm{M} \mathrm{HC1}$ medium," Corrosion Science, vol. 46, no. 10, pp. $2455-$ 2466, 2004

[3] K. C. Emregül, R. Kurtaran, and O. Atakol, "An investigation of chloride-substituted Schiff bases as corrosion inhibitors for steel," Corrosion Science, vol. 45, no. 12, pp. 2803-2817, 2003.

[4] M. A. Arenas, A. Conde, and J. J. De Damborenea, "Cerium: a suitable green corrosion inhibitor for tinplate," Corrosion Science, vol. 44, no. 3, pp. 511-520, 2002.

[5] E. Cano, P. Pinilla, J. L. Polo, and J. M. Bastidas, "Copper corrosion inhibition by fast green, fuchsin acid and basic compounds in citric acid solution," Materials and Corrosion, vol. 54, no. 4, pp. 222-228, 2003.

[6] D.-J. Choi, Y.-W. Kim, and J.-G. Kim, "Development of a blended corrosion, scale, and microorganism inhibitor for open recirculating cooling systems," Werkstoffe und Korrosion, vol. 52, no. 9, pp. 697-704, 2001.

[7] G. Moretti, F. Guidi, and G. Grion, "Tryptamine as a green iron corrosion inhibitor in $0.5 \mathrm{M}$ deaerated sulphuric acid," Corrosion Science, vol. 46, no. 2, pp. 387-403, 2004.

[8] S. A. Abd El-Maksoud, "The effect of organic compounds on the electrochemical behaviour of steel in acidic media-a review," International Journal of Electrochemical Science, vol. 3, pp. 528$555,2008$.

[9] M. A. Quraishi and R. Sardar, "Corrosion inhibition of mild steel in acid solutions by some aromatic oxadiazoles," Materials Chemistry and Physics, vol. 78, no. 2, pp. 425-431, 2003.

[10] M. Şahin, S. Bilgiç, and H. Yilmaz, "The inhibition effects of some cyclic nitrogen compounds on the corrosion of the steel in NaCl mediums," Applied Surface Science, vol. 195, no. 1-4, pp. $1-7,2002$.

[11] M. Abdallah, M. Al-Agez, and A. S. Fouda, "Phenylhydrazone derivatives as corrosion inhibitors for - $\alpha$-brass in hydrochloric acid solutions," International Journal of Electrochemical Science, vol. 4, no. 3, pp. 336-352, 2009.

[12] M. Bouklah, N. Benchat, A. Aouniti et al., "Effect of the substitution of an oxygen atom by sulphur in a pyridazinic molecule towards inhibition of corrosion of steel in $0.5 \mathrm{M} \mathrm{H}_{2} \mathrm{SO}_{4}$ medium," Progress in Organic Coatings, vol. 51, no. 2, pp. 118-124, 2004.

[13] H.-L. Wang, R.-B. Liu, and J. Xin, "Inhibiting effects of some mercapto-triazole derivatives on the corrosion of mild steel in 1.0 M HC1 medium," Corrosion Science, vol. 46, no. 10, pp. 24552466, 2004.

[14] M. Karakuş, M. Şahin, and S. Bilgiç, "An investigation on the inhibition effects of some new dithiophosphonic acid monoesthers on the corrosion of the steel in $1 \mathrm{MHCl}$ medium," Materials Chemistry and Physics, vol. 92, no. 2-3, pp. 565-571, 2005.

[15] A. A. Rahim, E. Rocca, J. Steinmetz, M. J. Kassim, R. Adnan, and M. S. Ibrahim, "Mangrove tannins and their flavanoid monomers as alternative steel corrosion inhibitors in acidic medium," Corrosion Science, vol. 49, no. 2, pp. 402-417, 2007.

[16] W. Li, Q. He, C. Pei, and B. Hou, "Experimental and theoretical investigation of the adsorption behaviour of new triazole derivatives as inhibitors for mild steel corrosion in acid media," Electrochimica Acta, vol. 52, no. 22, pp. 6386-6394, 2007.

[17] S. D. Shetty, P. Shetty, and H. V. S. Nayak, "The inhibition action of $\mathrm{N}$-furfuryl- $\mathrm{N}^{\prime}$-phenyl thiourea on the corrosion of mild steel in acid media," Journal of the Serbian Chemical Society, vol. 71, no. 10, pp. 1073-1082, 2006.

[18] K. F. Khaled and N. A. Al-Mobarak, "A predictive model for corrosion inhibition of mild steel by thiophene and its derivatives using artificial neural network," International Journal of Electrochemical Science, vol. 7, no. 2, pp. 1045-1059, 2012.

[19] M. Z. A. Rafiquee, N. Saxena, S. Khan, and M. A. Quraishi, "Some fatty acid oxadiazoles for corrosion inhibition of mild steel in HCl," Indian Journal of Chemical Technology, vol. 14, no. 6, pp. 576-583, 2007.

[20] E. E. Ebenso, T. Arslan, F. Kandemirli et al., "Quantum chemical studies of some Rhodanineazosulpha drugs as corrosion inhibitors for mild steel in acidic medium," International Journal of Quantum Chemistry, vol. 110, no. 14, pp. 2614-2636, 2010.

[21] O. I. Sizaya and A. P. Andrushko, "On the use of triazines as inhibitors of steel corrosion," Protection of Metals, vol. 40, no. 2, pp. 164-168, 2004.

[22] H. Ashassi-Sorkhabi, B. Shaabani, and D. Seifzadeh, "Corrosion inhibition of mild steel by some schiff base compounds in hydrochloric acid," Applied Surface Science, vol. 239, no. 2, pp. 154-164, 2005.

[23] S. Acharya and S. N. Upadhyay, "The inhibition of corrosion of mild steel by some fluoroquinolones in sodium chloride solution," Transactions of the Indian Institute of Metals, vol. 57, no. 3, pp. 297-306, 2004.

[24] M. Abdallah, M. Al-Agez, and A. S. Fouda, "Phenylhydrazone derivatives as corrosion inhibitors for $-\alpha$-brass in hydrochloric acid solutions," International Journal of Electrochemical Science, vol. 4, no. 3, pp. 336-352, 2009.

[25] M. A. Quraishi and D. Jamal, "Fatty acid triazoles: novel corrosion inhibitors for oil well steel (N-80) and mild steel," Journal of the American Oil Chemists' Society, vol. 77, no. 10, pp. 1107$1111,2000$.

[26] M. A. Quraishi, V. Bhardwaj, and J. Rawat, "Prevention of metallic corrosion by lauric hydrazide and its salts under vapor phase conditions," Journal of the American Oil Chemists' Society, vol. 79, no. 6, pp. 603-609, 2002.

[27] A. Singh, A. K. Singh, and M. A. Quraishi, "Dapsone: a novel corrosion inhibitor for mild steel in acid media," The Open Electrochemical Journal, vol. 2, pp. 43-51, 2010. 
[28] M. A. Quraishi and H. K. Sharma, "4-amino-3-butyl-5mercapto-1,2,4-triazole: a new corrosion inhibitor for mild steel in sulphuric acid," Materials Chemistry and Physics, vol. 78, no. 1, pp. 18-21, 2003.

[29] T. Poornima, J. Nayak, and A. N. Shetty, "Corrosion inhibition of the annealed $18 \mathrm{Ni} 250$ grade maraging steel in 0. $67 \mathrm{M}$ phosphoric acid by 3,4-dimethoxybenzaldehydethiosemicarbazone," Chemical Sciences Journal, vol. 69, pp. 1-14, 2012.

[30] M. Abdallah, E. A. Helal, and A. S. Fouda, "Aminopyrimidine derivatives as inhibitors for corrosion of 1018 carbon steel in nitric acid solution," Corrosion Science, vol. 48, no. 7, pp. 16391654, 2006.

[31] S. S. Abd El-Rehim, S. A. M. Refaey, F. Taha, M. B. Saleh, and R. A. Ahmed, "Corrosion inhibition of mild steel in acidic medium using 2-amino thiophenol and 2-cyanomethyl benzothiazole," Journal of Applied Electrochemistry, vol. 31, no. 4, pp. 429-435, 2001.

[32] A. Yurt, A. Balaban, S. U. Kandemir, G. Bereket, and B. Erk, "Investigation on some Schiff bases as $\mathrm{HCl}$ corrosion inhibitors for carbon steel," Materials Chemistry and Physics, vol. 85, no. 2-3, pp. 420-426, 2004.

[33] L. Tang, X. Li, Y. Si, G. Mu, and G. Liu, "The synergistic inhibition between 8-hydroxyquinoline and chloride ion for the corrosion of cold rolled steel in $0.5 \mathrm{M}$ sulfuric acid," Materials Chemistry and Physics, vol. 95, no. 1, pp. 29-38, 2006.

[34] A. K. Bhattacharya, T. K. Naiya, S. N. Mandal, and S. K. Das, "Adsorption, kinetics and equilibrium studies on removal of $\mathrm{Cr}(\mathrm{VI})$ from aqueous solutions using different low-cost adsorbents," Chemical Engineering Journal, vol. 137, no. 3, pp. 529-541, 2008.

[35] S. A. M. Refaey, F. Taha, and A. M. Abd El-Malak, "Corrosion and inhibition of $316 \mathrm{~L}$ stainless steel in neutral medium by 2 mercaptobenzimidazole," International Journal of Electrochemical Science, vol. 1, pp. 80-91, 2006.

[36] M. Lagrenée, B. Mernari, M. Bouanis, M. Traisnel, and F. Bentiss, "Study of the mechanism and inhibiting efficiency of 3,5bis(4-methylthiophenyl)-4H-1,2,4-triazole on mild steel corrosion in acidic media," Corrosion Science, vol. 44, no. 3, pp. 573$588,2002$.

[37] S. A. Umoren and E. E. Ebenso, "The synergistic effect of polyacrylamide and iodide ions on the corrosion inhibition of mild steel in $\mathrm{H}_{2} \mathrm{SO}_{4}$," Materials Chemistry and Physics, vol. 106, no. 2-3, pp. 387-393, 2007.

[38] M. Elayyachy, A. El Idrissi, and B. Hammouti, "New thiocompounds as corrosion inhibitor for steel in $1 \mathrm{M} \mathrm{HCl,"} \mathrm{Corro-}$ sion Science, vol. 48, no. 9, pp. 2470-2479, 2006.

[39] F. M. Bayoumi and W. A. Ghanem, "Corrosion inhibition of mild steel using naphthalene disulfonic acid," Materials Letters, vol. 59, no. 29-30, pp. 3806-3809, 2005.

[40] A. Yurt, A. Balaban, S. U. Kandemir, G. Bereket, and B. Erk, "Investigation on some Schiff bases as $\mathrm{HCl}$ corrosion inhibitors for carbon steel," Materials Chemistry and Physics, vol. 85, no. 2-3, pp. 420-426, 2004.

[41] X. Li, S. Deng, H. Fu, and T. Li, "Adsorption and inhibition effect of 6-benzylaminopurine on cold rolled steel in 1.0 M HCl," Electrochimica Acta, vol. 54, no. 16, pp. 4089-4098, 2009.

[42] M. Lebrini, F. Bentiss, H. Vezin, and M. Lagrenée, "Inhibiting effects of some oxadiazole derivatives on the corrosion of mild steel in perchloric acid solution," Applied Surface Science, vol. 252, no. 4, pp. 950-958, 2005.
[43] A. Y. Musa, A. A. H. Kadhum, A. B. Mohamad, M. S. Takriff, A R. Daud, and S. K. Kamarudin, "On the inhibition of mild steel corrosion by 4-amino-5-phenyl-4H-1, 2, 4-trizole-3-thiol," Corrosion Science, vol. 52, no. 2, pp. 526-533, 2010.

[44] K. Jüttner, "Electrochemical Impedance Spectroscopy (EIS) of corrosion processes on inhomogeneous surfaces," Electrochimica Acta, vol. 35, no. 10, pp. 1501-1508, 1990.

[45] F. Bentiss, M. Lebrini, M. Lagrenée, M. Traisnel, A. Elfarouk, and H. Vezin, "The influence of some new 2,5-disubstituted 1,3,4-thiadiazoles on the corrosion behaviour of mild steel in $1 \mathrm{M} \mathrm{HCl}$ solution: AC impedance study and theoretical approach," Electrochimica Acta, vol. 52, no. 24, pp. 6865-6872, 2007.

[46] F. El-Taib Heakal, A. A. Ghoneim, and A. M. Fekry, "Stability of spontaneous passive films on high strength Mo-containing stainless steels in aqueous solutions," Journal of Applied Electrochemistry, vol. 37, no. 3, pp. 405-413, 2007.

[47] M. Lebrini, F. Bentiss, H. Vezin, and M. Lagrenée, "The inhibition of mild steel corrosion in acidic solutions by 2,5bis(4-pyridyl)-1,3,4-thiadiazole: structure-activity correlation," Corrosion Science, vol. 48, no. 5, pp. 1279-1291, 2006.

[48] S. K. Shukla and M. A. Quraishi, "The effects of pharmaceutically active compound doxycycline on the corrosion of mild steel in hydrochloric acid solution," Corrosion Science, vol. 52, no. 2, pp. 314-321, 2010.

[49] F. Bentiss, M. Traisnel, and M. Lagrenee, "The substituted 1,3,4oxadiazoles: a new class of corrosion inhibitors of mild steel in acidic media," Corrosion Science, vol. 42, no. 1, pp. 127-146, 2000.

[50] K. Parameswari, S. Chitra, C. N. Unnisa, and A. Selvaraj, "Effect of azlactones on corrosion inhibition of mild steel in acid medium," Journal of Applied Sciences Research, vol. 6, no. 8, pp. 1100-1110, 2010.

[51] S. Aloui, I. Forsal, M. Sfaira et al., "New mechanism synthesis of 1,4-benzothiazine and its inhibition performance on mild steel in hydrochloric acid," Portugaliae Electrochimica Acta, vol. 27, no. 5, pp. 599-613, 2009.

[52] I. Zaafarany, "Phenyl phthalimide as corrosion inhibitor for corrosion of C-Steel in sulphuric acid solution," Portugaliae Electrochimica Acta, vol. 27, no. 5, pp. 631-643, 2009.

[53] M. Behpour, S. M. Ghoreishi, M. Salavati-Niasari, and B. Ebrahimi, "Evaluating two new synthesized S-N Schiff bases on the corrosion of copper in 15\% hydrochloric acid," Materials Chemistry and Physics, vol. 107, no. 1, pp. 153-157, 2008.

[54] I. Ahamad and M. A. Quraishi, "Bis (benzimidazol-2-yl) disulphide: an efficient water soluble inhibitor for corrosion of mild steel in acid media," Corrosion Science, vol. 51, no. 9, pp. 20062013, 2009. 

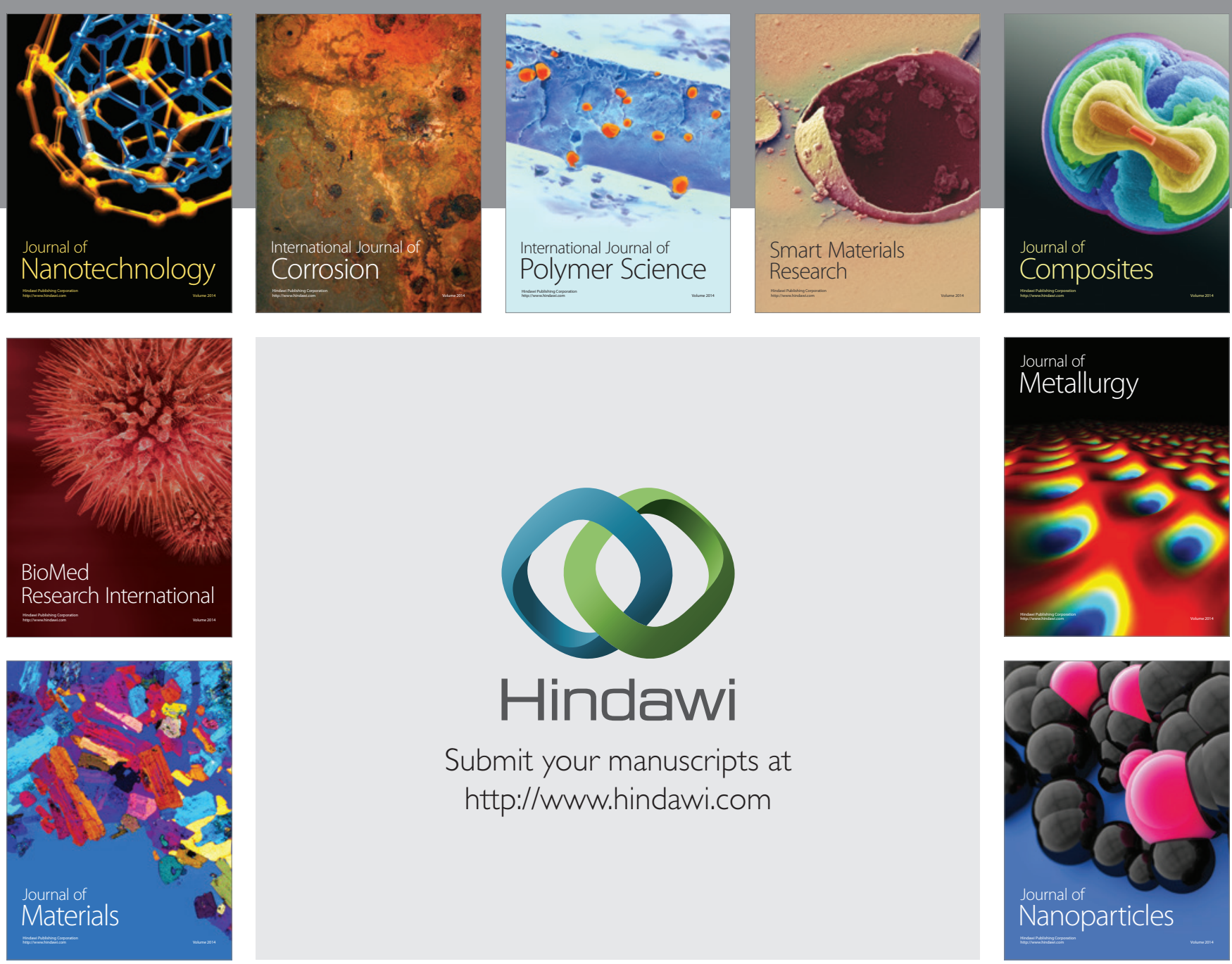

Submit your manuscripts at http://www.hindawi.com
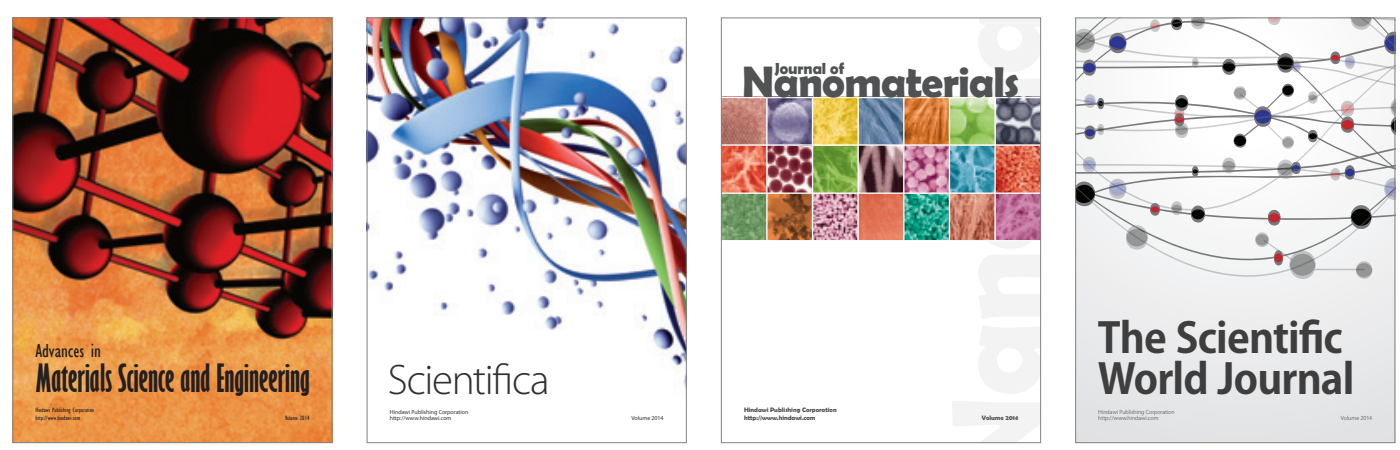

\section{The Scientific World Journal}
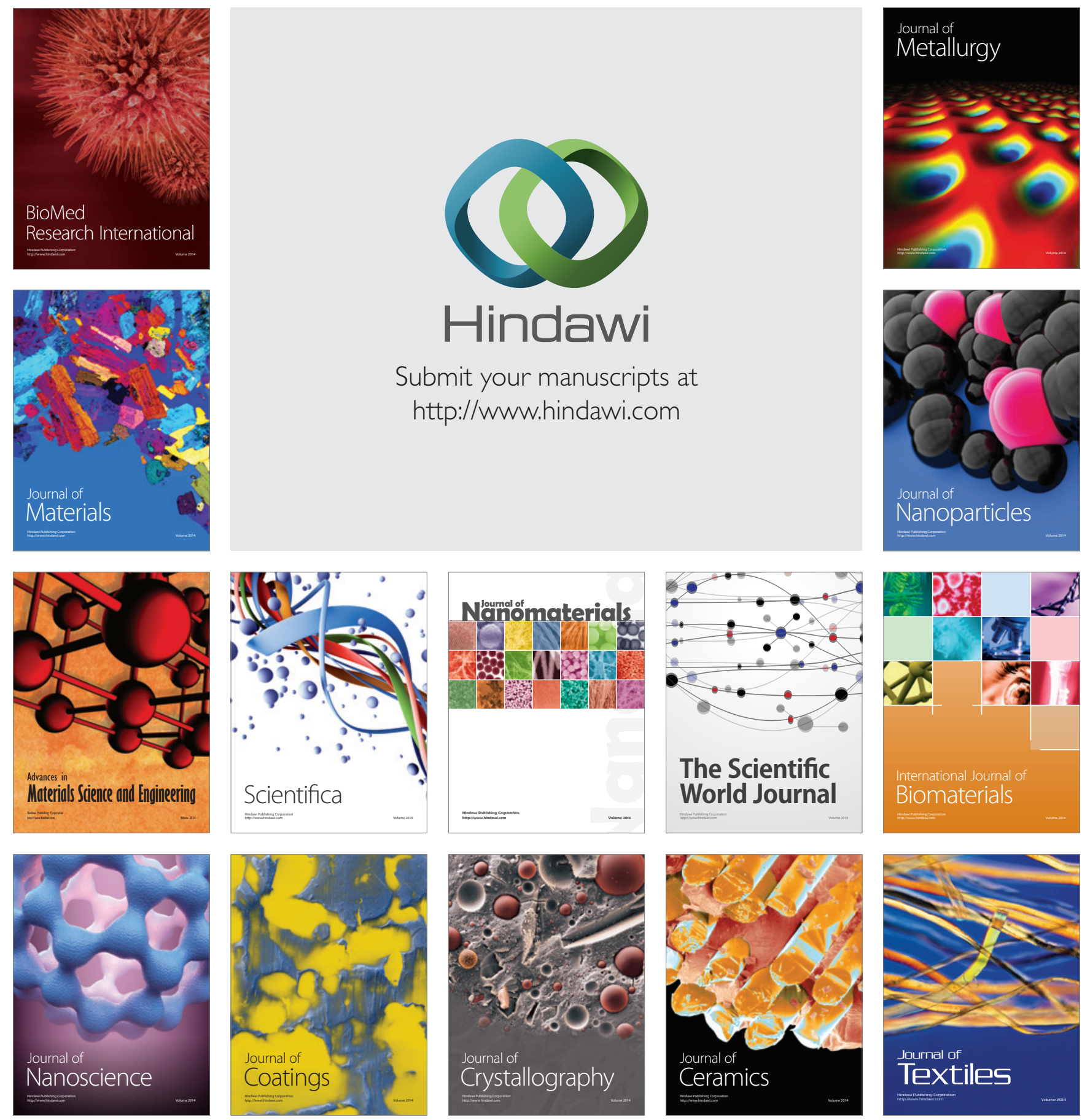